\title{
Polylactide-co-glycolide nanoparticles for controlled delivery of anticancer agents
}

This article was published in the following Dove Press journal:

International Journal of Nanomedicine

26 April 201 I

Number of times this article has been viewed

\section{R Dinarvand ${ }^{1,2}$ \\ N Sepehri' \\ S Manoochehri' \\ H Rouhani' \\ F Atyabi ${ }^{1,2}$}

'Department of Pharmaceutics, Faculty of Pharmacy, ${ }^{2}$ Nanotechnology Research Centre, Tehran University of Medical Sciences, Tehran, Iran
Correspondence: R Dinarvand Department of Pharmaceutics, Faculty of Pharmacy, Tehran University of Medical Sciences, PO Box 14155-645I, Tehran, Iran Tel +982166959095

Fax +98 21 66959096

Email dinarvand@tums.ac.ir
Abstract: The effectiveness of anticancer agents may be hindered by low solubility in water, poor permeability, and high efflux from cells. Nanomaterials have been used to enable drug delivery with lower toxicity to healthy cells and enhanced drug delivery to tumor cells. Different nanoparticles have been developed using different polymers with or without surface modification to target tumor cells both passively and/or actively. Polylactide-co-glycolide (PLGA), a biodegradable polyester approved for human use, has been used extensively. Here we report on recent developments concerning PLGA nanoparticles prepared for cancer treatment. We review the methods used for the preparation and characterization of PLGA nanoparticles and their applications in the delivery of a number of active agents. Increasing experience in the field of preparation, characterization, and in vivo application of PLGA nanoparticles has provided the necessary momentum for promising future use of these agents in cancer treatment, with higher efficacy and fewer side effects.

Keywords: nanotechnology, polymeric nanocarriers, targeting, anticancer agents, surface modification

\section{Introduction}

Recent developments in nanotechnology have enabled new research strategies to flourish in the field of drug delivery. There has been considerable interest in developing nanoparticles as effective drug carriers. ${ }^{1}$ For pharmaceutical purposes, nanoparticles are defined as solid colloidal particles ranging in size from $10 \mathrm{~nm}$ to $400 \mathrm{~nm}$. They consist of macromolecular materials in which the active agent (drug or biologically active material) is dissolved, entrapped, and/or encapsulated, or to which the active agent is adsorbed or attached. ${ }^{2}$

Drug delivery has been improved with the translation of several nanoscale drug delivery systems into the clinic, although the full potential of these systems is only now starting to be explored. Nanoscale drug delivery systems have shown the ability to encapsulate a variety of therapeutic agents, such as small molecules (hydrophilic and/or hydrophobic), peptide protein-based drugs, and nucleic acids. By encapsulating these molecules inside a nanocarrier, the solubility and stability of drugs can be improved, providing an opportunity to re-evaluate the therapeutic potential of drugs previously discounted because of poor pharmacokinetics. ${ }^{3}$

The diversity of drug delivery systems allows nanoparticles to be developed with a diverse array of shapes, sizes, and components, enabling them to be tailored for specific applications. However, the primary consideration when designing any drug delivery system is to control the drug concentration in the therapeutic window, while 
reducing side effects and improving patient compliance. This allows effective treatment cycles to be maintained, and at the same time reduces damage to healthy cells and minimizes the recovery period. ${ }^{4-6}$

Langer and Folkman were the first to demonstrate the controlled release of macromolecules using polymers, which enabled the development of antiangiogenic drug delivery systems for cancer therapy and opened up new areas for the delivery of macromolecules. ${ }^{7}$

Polymeric nanoparticles provide significant flexibility in design because different polymers from synthetic or natural sources can be used. Polymeric nanoparticles may represent the most effective nanocarriers for targeted drug delivery. Some common polymers used for nanoparticle formation include polylactide-co-glycolide (PLGA), polylactic acid, dextran, and chitosan. Biodegradable polymers are typically degraded into oligomers and individual monomers, which are metabolized and removed from the body via normal pathways. $^{8-10}$

Degradation and drug release kinetics can be precisely controlled by the physicochemical properties of the polymer, such as molecular weight, polydispersity index, hydrophobicity, and crystallinity. In general, drugs can be released in a controlled manner following Fickian kinetics due to drug diffusion through the polymeric matrix, or be triggered in response to environmental stimuli or released in the course of chemical degradation. The nanoparticle surface may be sterically stabilized by grafting, conjugating, or adsorbing hydrophilic polymers, such as polyethylene glycol (PEG), to its surface, which can reduce hepatic uptake and improve the circulation half-life of the nanoparticles. ${ }^{11,12}$ PLGA is one of the most commonly used degradable polymers and is discussed extensively here.

\section{Properties of PLGA}

PLGA has generated tremendous interest due to its excellent biocompatibility, biodegradability, and mechanical strength (Figure 1). ${ }^{13}$ PLGA can be synthesized by a polycondensation reaction or via ring-opening polymerization of cyclic diesters. Ring-opening polymerization is currently the preferred method for the synthesis for PLGA and polylactic acid due to shorter reaction times and higher monomer conversion rates. ${ }^{14}$ The discovery and synthetic work on low molecular weight oligomeric forms of lactide and/or glycolide polymers were first carried out several decades ago. ${ }^{15} \mathrm{~A}$ method to synthesize high molecular weight forms of such polymers was first reported by Lowe. ${ }^{16}$ During the late 1960s and early 1970s, a number of groups published their pioneering work

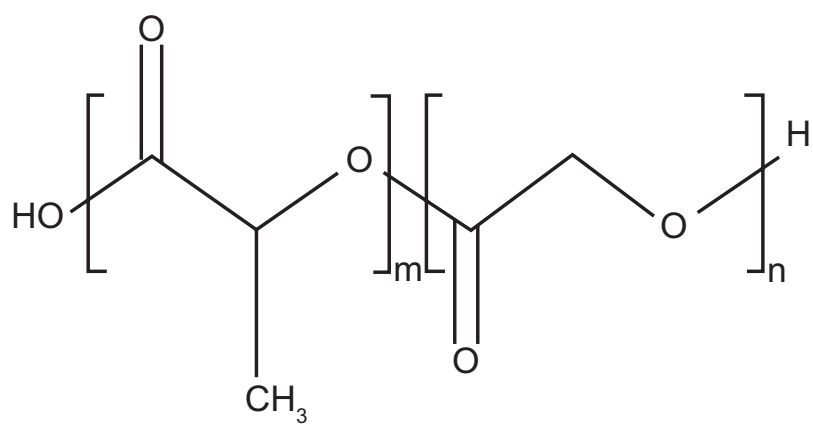

Figure I Chemical structure of polylactide-co-glycolide.

Abbreviations: $m$, number of units of lactide acid, $n$, number of units of glycolic acid.

on the utility of these polymers in the manufacture of sutures and fibers. ${ }^{15,16}$ Since then, these polymers have been used in a broad range of pharmaceutical and biomedical applications. Various polymeric devices, such as microspheres, microcapsules, nanoparticles, pellets, implants, and films have been fabricated using these polymers. They are also easy to formulate into various delivery systems for carrying a variety of active agents, such as vaccines, peptides, proteins, and micromolecules, some of which are now approved by the Food and Drug Administration for use in drug delivery. ${ }^{14-18}$

In order to improve the formulation of controlled drug delivery devices, an understanding of the physical, chemical, and biological properties of polymers is helpful. The polylactic acid polymer can exist in an optically active stereoregular form (L-polylactic acid) and in an optically inactive racemic form (D, L-polylactic acid). L-polylactic acid is semicrystalline in nature due to the high regularity of its polymer chain structure, while D, L-polylactic acid is an amorphous polymer because of irregularities in its polymer chain structure. Polyglycolide is highly crystalline because it lacks the methyl side groups of polylactic acid. ${ }^{15}$ PLGA copolymers prepared from L-polylactic acid and polyglycolide are crystalline, while those from D, L-polylactic acid and polyglycolide are amorphous in nature. It has been found that PLGAs containing less than $70 \%$ glycolide are amorphous. The degree of crystallinity and the melting point of the polymers are directly related to their molecular weight. The mechanical strength, swelling behavior, capacity to undergo hydrolysis, and, subsequently, the biodegradation rate, are directly influenced by the crystallinity of the PLGA polymer, which depends on the type and molar ratio of the individual monomer components (lactide and glycolide) in the copolymer chain. ${ }^{15,19}$ Lactic acid is more hydrophobic than glycolic acid and, therefore, lactide-rich PLGA copolymers are less hydrophilic, absorb less water, and subsequently, degrade more slowly. ${ }^{20,21}$ 
The glass transition temperatures of PLGA copolymers are above the physiological temperature of $37^{\circ} \mathrm{C}$, and hence they are normally glassy in nature, with sufficient strength to be formulated as a drug delivery system. The glass transition temperatureof a PLGA copolymer decreases with reducing molecular weight and lactide content. ${ }^{15}$

\section{Mechanism of biodegradation of PLGA}

A fundamental understanding of the in vivo phenomenon of PLGA biodegradation is important because this determines the rate and mechanism of the release of therapeutic agents. The therapeutic agent is either dispersed throughout the polymeric matrix or encapsulated in the hydrophobic nanoparticle core. The release of a therapeutic agent from nanoparticles has usually been shown to be biphasic, initially by diffusion through the polymer matrix and later bydiffusion of the therapeutic agent and degradation of the polymer matrix itself. ${ }^{22,23}$ PLGA copolymers are degraded in the body by hydrolytic cleavage of the ester linkage to lactic and glycolic acid (Figure 2). These monomers are easily metabolized in the body via the Krebs cycle and eliminated as carbon dioxide and water. ${ }^{15,24}$

The polymer degradation process both in vitro and in vivo is affected by several factors, including the method of preparation, the presence of low molecular weight compounds (monomers, oligomers, catalysts), size, shape and morphology, the intrinsic properties of the polymer (molecular weight, chemical structure, hydrophobicity, crystallinity, and glass transition temperature), ${ }^{15}$ physicochemical parameters $(\mathrm{pH}$, temperature, and ionic strength of the environment), site of implantation, and mechanism of hydrolysis. In general, the degradation time will be shorter for low molecular weight, more hydrophilic, and more amorphous polymers, and for copolymers with a higher glycolide content.

Although PLGA copolymers can undergo surface erosion in some conditions, bulk erosion is the main degradation pathway (Figure 3). This occurs by random scission of ester bonds in the polymer backbone occurring homogeneously throughout the device. ${ }^{18} \mathrm{~A}$ three-phase mechanism for PLGA biodegradation has been proposed. Initially, a significant decrease in the molecular weight of the polymer is observed, with no appreciable weight loss and no soluble monomer products formed after random chain scission. This phase is followed by a decrease in molecular weight, with rapid loss of mass and formation of soluble monomeric and oligomeric products. Finally, soluble monomer products are formed from soluble oligomeric fragments, resulting in complete polymer degradation. ${ }^{15}$

\section{Methods for preparation of PLGA nanoparticles}

Several methods for polymeric nanoparticle production have been developed by researchers. These methods generally include two main steps. The first step is to prepare an emulsified system, and this is common to all the methods used. The nanoparticles are formed during the second step, which varies according to the method used. In general, the principle of this second step gives its name to the method. Some methods do not require the preparation of an emulsion prior to obtaining the nanoparticles, and are based on spontaneous precipitation of a polymer or through self assembly of macromolecules. ${ }^{25}$ The commonly used methods for preparation of PLGA nanoparticles are briefly described.

\section{Emulsification solvent evaporation}

Emulsification solvent evaporation is one of the most frequently used methods. The polymer and the drug are first dissolved in a water-immiscible volatile solvent, such as dichloromethane or chloroform, which is then emulsified in an aqueous solution containing a stabilizer. The emulsification is brought about by subsequent exposure to a high-energy shearing source, such as an ultrasonic device or homogenizer. The organic phase is evaporated under reduced pressure or vacuum, resulting in a fine aqueous dispersion of nanoparticles. The nanoparticles are collected by ultracentrifugation and washed with distilled water to remove stabilizer residues or any free drug, and then lyophilized for storage. ${ }^{1,26,27}$

The emulsion evaporation method can be used for the preparation of particles with sizes varying from a few

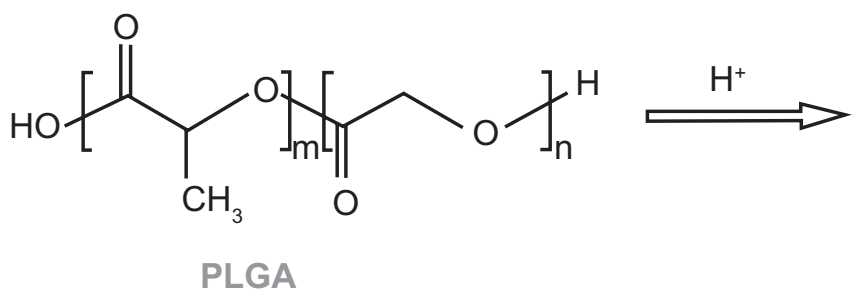<smiles>CC(O)C(=O)O</smiles>

Figure 2 Degradation of polylactide-co-glycolide to lactic and glycolic acid. 

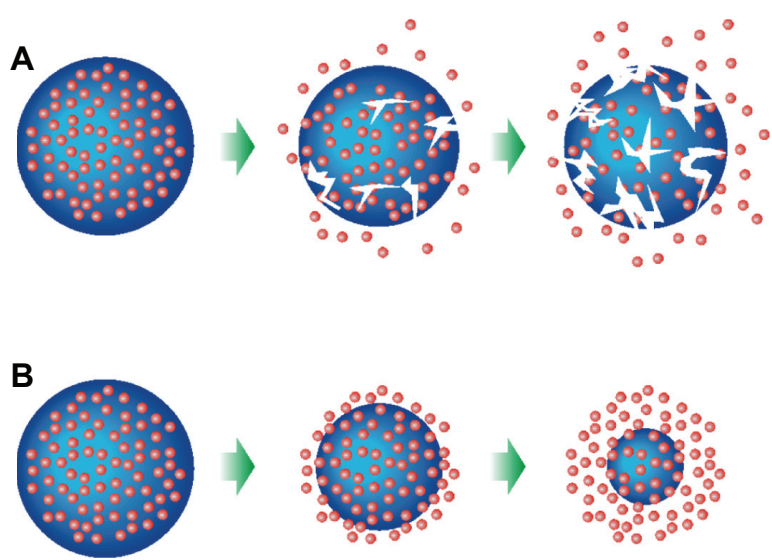

Figure 3 Degradation mechanisms of biodegradable polymeric nanoparticles: A) bulk erosion, B) surface erosion.

nanometers to micrometers by controlling the stirring rates and conditions, and shows high efficiency forthe incorporation of lipophilic drugs. ${ }^{28-30}$ To entrap hydrophilic drugs, the double-emulsion technique is employed, which involves the addition of aqueous drug solution to organic polymer solution under vigorous stirring to form a water-in-oil emulsion. This water-in-oil emulsion is added into a second aqueous phase containing a stabilizer with stirring to form the water-in-oilin-water emulsion. The emulsion is then subjected to solvent removal by evaporation. ${ }^{31,32}$

\section{Emulsification solvent diffusion}

This method is also known as emulsification and solvent displacement. The solvent used to prepare the emulsion needs to be partly soluble in water. ${ }^{33}$ The polymeric solution is added to an aqueous solution, containing stabilizer, under vigorous stirring. ${ }^{18}$ Once the oil-in-water emulsion is obtained, it is diluted with a large quantity of pure water. As a result of this dilution, additional organic solvent from the organic phase contained in the dispersed droplets can diffuse out of the droplets, leading to precipitation of the polymer. Suitable solvents include benzyl alcohol, propylene carbonate, ethyl acetate, isopropyl acetate, methyl acetate, methyl ethyl ketone, benzyl alcohol, butyl lactate, and isovaleric acid. This method has been used for PLGA nanoparticle preparation in many studies. ${ }^{34-37}$ It should be noted that the solvent evaporation process is similar to this method, in the sense that the solvent must first diffuse out into the external aqueous dispersion medium before it can be removed from the system by evaporation. ${ }^{25}$

\section{Emulsification reverse salting-out}

The emulsification reverse salting-out technique involves the addition of polymerand drug solution to a water-miscible solvent, such as acetone, and to an aqueous solution containing the salting-out agent, such as magnesium chloride, calcium chloride, and a colloidal stabilizer, such as polyvinyl pyrrolidone, under vigorous mechanical stirring. When this oil-in-water emulsion is diluted with a sufficient volume of water, it induces the formation of nanoparticles by enhancing the diffusion of acetone into the aqueous phase. The dilution produces a sudden decrease in the salt concentration in the continuous phase of the emulsion, inducing the polymer solvent to migrate out of the emulsion droplets. The remaining solvent and salting-out agent are eliminated by cross-flow filtration. ${ }^{1,38,39}$ Although the emulsification-diffusion method is a modification of the salting-out procedure, it has the advantage of avoiding the use of salts and thus eliminates the need for intensive purification steps. ${ }^{18}$

\section{Nanoprecipitation}

The nanoprecipitation method is a one-step procedure, also known as the solvent displacement method. ${ }^{40}$ It is usually employed to incorporate lipophilic drugs into the carriers based on the interfacial deposition of a polymer. ${ }^{41,42}$ Nanoprecipitation is performed using systems containing three basic ingredients, ie, the polymer, the polymer solvent, and the nonsolvent of the polymer. The solvent should be organic, miscible in water, and easily removed by evaporation. For this reason, acetone is the most frequently used solvent with this method..$^{43}$ Sometimes it exists as a binary blend of solvents, as acetone with a small amount of water, or as a blend of ethanol and acetone. Polymer, drug, and lipophilic surfactant (eg, phospholipids) are dissolved in a semipolar watermiscible solvent, such as acetone or ethanol. The solution is then poured or injected into an aqueous solution containing stabilizer under magnetic stirring. Nanoparticles are formed immediately by rapid solvent diffusion. The solvent is then removed from the suspension under reduced pressure. ${ }^{15,18}$

\section{Nanoparticle characterization techniques}

Characterization of nanoparticles is essential for a thorough understanding of their properties before developing them further for pharmaceutical application. Nanoparticle size is critical, not only in determining the release profile and degradation behavior, but also in determining the efficacy of the therapeutic agent in terms of tissue penetration and cellular uptake. ${ }^{44}$ The molecular weight of the polymer influences the nanoparticle size, encapsulation efficiency, and degradation rate of the polymer, hence affecting the release rate of the therapeutic agent, ${ }^{45}$ as shown by Konan et al who 
demonstrated that the molecular weight of PLGA impacts the final mean nanosphere size. In general, higher molecular weights form nanoparticles of larger size. Change in nanoparticle size has been evaluated according to changes in PLGA composition and molecular weight (12-48 kDa for 50:50 PLGA and 12-98 kDa for 75:25 PLGA). ${ }^{39}$ For the nanospheres with 50:50 PLGA, mean size ranged from $102 \pm 4 \mathrm{~nm}$ to $154 \pm 17 \mathrm{~nm}$ for $12 \mathrm{kDa}$ and $48 \mathrm{kDa}$, respectively. For the 75:25 PLGA, nanoparticle mean size ranged from $132 \pm 3 \mathrm{~nm}$ to $152 \pm 25 \mathrm{~nm}$ for $12 \mathrm{kDa}$ and $98 \mathrm{kDa}$, respectively.

In another study, Mittal et al prepared estradiol-loaded PLGA nanoparticles with different molecular weights $(14.5,45,85,135$, and $213 \mathrm{kDa})$ by the emulsion-diffusionevaporation method, and showed that entrapment efficiency did not follow a regular pattern. First, it decreased from $51.3 \%$ to $34.5 \%$ as molecular weight was increased from about $14.5 \mathrm{kDa}$ to $85 \mathrm{kDa}$, and, thereafter, a significant increase $(P<0.05)$ to $67.8 \%$ was observed as molecular weight was increased to $213 \mathrm{kDa}$. Entrapment efficiency of particles using the oil-in-water method depends mainly on the drug partition coefficient in the internal and external phases. It is possible that an increase in viscosity on increasing the molecular weight might have decreased the diffusion rate of the solvent into the external aqueous phase. The polymer precipitated slowly because of a slow rate of solvent removal, giving the drug molecules more time to come into the aqueous phase, resulting in low entrapment efficiency. However, an increase inentrapment efficiency was observed for particles with molecular weights of $137 \mathrm{kDa}$ and $213 \mathrm{kDa}$, which could be due to strong hydrophobic interaction between the molecular chains of the polymer and the drug. ${ }^{46}$

An increase in molecular weight from $14.5 \mathrm{kDa}$ to $213 \mathrm{kDa}$ was associated with a significant decrease in the rate of release of estradiol. Molecular weight is indicative of polymer chain length, and the higher the molecular weight, the longer the chain length. Furthermore, chain length reflects the hydrophilicity or lipophilicity of the polymer. An increase in chain length increases the lipophilicity and decreases the degradation rate of the polymer. Therefore, by varying the molecular weight, the degradation rate of the polymer and release kinetics of the drug can be controlled..$^{15,46}$

The physical state of both the drug and the polymer need to be determined because this will have an influence on the in vitro and in vivo drug release characteristics. The zeta potential can influence particle stability and mucoadhesion, as well as intracellular trafficking of nanoparticles as a function of $\mathrm{pH}$. Hydrophobicity determines the distribution of nanoparticles in the body after administration. Hydrophilic particles tend to remain in the blood for a longer time..$^{18,27,47}$ There are many sensitive techniques for characterizing nanoparticles, depending upon the parameter being investigated. These techniques are summarized in Table 1.

\section{PLGA nanoparticles for drug delivery to tumors}

Cancer is a worldwide public health problem, and tens of millions of people presently suffer from this deadly disease. ${ }^{82}$ Cancer research involves intensive scientific efforts to identify the causes of cancer and to develop specific strategies for its prevention, diagnosis, treatment, and cure. Despite considerable progress in its early diagnosis, but progress concerning its treatment has been less so. In current anticancer therapy, drugs are administered via the intravenous and/or oral route using conventional formulations, including injections, tablets, and capsules. Controlled and targeted delivery of an anticancer agent at the site of action is necessary to maximize the killing effect during the tumor growth phase and to avoid drug exposure to healthy adjacent cells, thereby reducing drug toxicity. It is also desirable to maintain a steady rate of infusion of the drug into the tumor to maximize exposure to dividing cells, resulting in tumor regression. ${ }^{83}$

Development of novel systems for delivery of anticancer drugs is a recent topic of research. Abraxane ${ }^{\circledR}$, an albumin-based formulation of paclitaxel from Abraxis Oncology, Nanoxel ${ }^{\circledR}$, a nanoliposome containing paclitaxel from DaburPharma, and Doxil ${ }^{\circledR}$, a nanoliposome containing doxorubicin from Ortho Biotech, are now well-known commercial products. ${ }^{82,84-89}$

Table I Techniques for polylactide-co-glycolide nanoparticle characterization

\begin{tabular}{ll}
\hline $\begin{array}{l}\text { Particle size, size } \\
\text { distribution, morphology }\end{array}$ & $\begin{array}{l}\text { Dynamic light scattering or } \\
\text { photon correlation spectroscopy }\end{array}$ \\
& Scanning electron microscopy ${ }^{28,50,51}$ \\
& Transmission electron microscopy \\
& Atomic force microscopy \\
& Size exclusion chromatography \\
Molecular weight & X-ray photoelectron spectroscopy \\
Surface chemistry & Fourier transform infrared spectroscopy \\
analysis & Nuclear magnetic resonance spectroscopy \\
& Zetasizer \\
Surface charge & X-ray diffraction \\
Crystallinity & Differential scanning calorimetry \\
& Water contact angle measurements \\
Hydrophobicity, & Hydrophobic interaction chromatography \\
hydrophilicity & Size exclusion chromatography \\
Drug entrapment & High-performance liquid \\
efficiency, drug & chromatography \\
release studies &
\end{tabular}


Nanoparticle-based drug delivery systems have many advantages for anticancer drug delivery, including an ability to pass through the smallest capillary vessels, because of their very small volume, and being able to avoid rapid clearance by phagocytes, so that their presence in the blood stream is greatly prolonged. ${ }^{90}$ Nanoparticles can also penetrate cells and gaps in tissue to arrive at target organs, including the liver, spleen, lung, spinal cord, and lymph. They may have controlled-release properties due to their biodegradability, $\mathrm{pH}$, ions, and/or temperature sensitivity. All these properties can improve the utility of anticancer drugs and reduce their toxic side effects.

PLGA nanoparticles linked to targeting ligands are used to target malignant tumors with high affinity. PLGA nanoparticles also have large surface areas and functional groups for conjugating to multiple diagnostic (eg, optical, radioisotopic, or magnetic) agents. ${ }^{91}$ Nanoparticle carriers have high stability in biological fluids, and are more able to avoid enzymatic metabolism than other colloidal carriers, such as liposomes or lipid vesicles. ${ }^{92}$ Most anticancer drugs that have been investigated in PLGA nanoparticle preparations are discussed below. They are also summarized in Table 2 .

\section{Paclitaxel}

Many anticancer drugs can be used clinically to treat various cancers, but have limited efficacy due to poor cell penetration. For example, paclitaxel, a mitotic inhibitor, has had limited clinical application because of its low therapeutic index, and its low solubility in water and many other pharmaceutical solvents acceptable for intravascular administration. Incorporation of paclitaxel into PLGA nanoparticles strongly enhances its antitumoral efficacy compared with the free drug $\left(\right.$ Taxol $\left.^{\circledR}\right)$, with this effect being more relevant after more prolonged incubation with cells. Based on these results, it can be concluded that the formulations developed so far may be considered promising systems for in vivo paclitaxel delivery. ${ }^{49}$

In an animal model, Van Vlerken et al encapsulated paclitaxel and the apoptotic signaling molecule, C6-ceramide, into a PLGA/poly ( $\beta$-amino ester)-blended polymer. When this nanoparticle formulation was administered intravenously to MCF7 and $\mathrm{MCF}_{\mathrm{TR}}$-tumor-bearing mice, higher concentrations of paclitaxel were found in the blood due to a longer retention time and enhanced tumoral accumulation compared with the free drug. In addition, the PLGA/poly ( $\beta$-amino ester)-blended nanoparticles were effective in enhancing the residence time of both drugs at the tumor site by reducing systemic clearance..$^{93}$
In another study, Feng et al developed paclitaxel-loaded nanoparticles to achieve better therapeutic effects with minimum side effects. In this investigation, phospholipids, cholesterol, and vitamins were used to replace traditional chemical emulsifiers to achieve high encapsulation efficacy and the desired drug release rate. ${ }^{94}$

The methodology and experimental parameters used for nanoparticle preparation can impact the physicochemical properties of the resulting formulations. Danhier et al have reported significantly higher encapsulation efficacies for paclitaxel loaded into PLGA nanoparticles using the nanoprecipitation method (70\%) compared with the emulsion/ solvent evaporation technique (40\%). ${ }^{59}$ Elsewhere, it was shown that an increase in the oil-to-water phase ratio ${ }^{49}$ and the polymer concentration of the organic phase ${ }^{95}$ could enhance the entrapment efficacy of paclitaxel within polyester-based nanoparticles produced by the nanoprecipitation technique. Alternatively, the organic solvent can be dialyzed against water to obtain polyester-based nanoparticles incorporating paclitaxel..$^{96-99}$

$\mathrm{Mu}$ and Feng used $\alpha$-tocopheryl polyethylene glycol 1000 succinate (vitamin E TPGS) as well as a matrix material with other biodegradable polymers for the fabrication of a nanoparticle formulation of paclitaxel. They concluded that vitamin E TPGS was advantageous either as an emulsifier or as matrix material blended with PLGA for the manufacture of nanoparticles enabling controlled release of paclitaxel. ${ }^{28}$

Surfactants and stabilizers are used to increase the physical stability of nanoparticles. Reports of the positive surface charge of a quaternary ammonium salt, didodecyl dimethyl ammonium bromide (DMAB), provided the incentive to aid the delivery of paclitaxel, because it was expected to ensure better interaction with the negatively charged cell membrane. This could result in increased retention time at the cell surface, thus increasing particle uptake. ${ }^{100}$ In another study, the safety and utility of DMAB for stabilizing PLGA nanoparticles was studied. The preliminary data from this study provide proof-of-concept of improved efficacy and safety of oral paclitaxel chemotherapy. ${ }^{101}$

\section{Docetaxel}

PLGA nanoparticles containing docetaxel with the desired size and drug-loading characteristics suitable for intravenous administration can be prepared without using Tween ${ }^{\circledR} 80$. Esmaeili et al showed that the cellular cytotoxicity of the nanoparticles was higher than for the free drug. Docetaxel-loaded nanoparticles reached good plasma levels in vivo in comparison with a conventional formulation 
Table 2 Summary of polylactide-co-glycolide nanoparticles

\begin{tabular}{|c|c|c|c|c|c|c|c|}
\hline $\begin{array}{l}\text { Polymer for } \\
\text { nanoparticle } \\
\text { preparation }\end{array}$ & Drug & Size $(\mathrm{nm})$ & $\begin{array}{l}\text { Zeta potential } \\
(\mathrm{mV})\end{array}$ & $\begin{array}{l}\text { EE } \\
(\% \mathrm{w} / \mathrm{w})\end{array}$ & $\begin{array}{l}\text { Loading } \\
(\% \text { w/w ) }\end{array}$ & Cell line & Reference \\
\hline PLGA & Paclitaxel & $<200$ & $(-23)-(-3 \mathrm{I})$ & $70-90$ & 1 & $\mathrm{NCl}-\mathrm{H} 69$ (SCLC) & 49,81 \\
\hline PEGylated PLGA & Paclitaxel & 112 & $-0.556 \pm 5.7$ & 70 & & HeLa & 59 \\
\hline PLGA & Paclitaxel & 300 & -20 & 75 & 4 & C6 glioma & 97 \\
\hline PLGA & Paclitaxel & $270-500$ & & 50 & 2.4 & & 28 \\
\hline PLGA & Docetaxel & 172 & -12.2 & 68 & 0.34 & T47D, MCF7, SKOV3, A549 & 102 \\
\hline PLGA & Docetaxel & 150 & -6 & 16.8 & 0.5 & & 73 \\
\hline PLGA-mPEG & Cisplatin & $150-160$ & & & 2 & HT29 cells & 103 \\
\hline PLGA-mPEG & Cisplatin & $130-160$ & $(-5.7)-(-9.3)$ & & $1.99-2.96$ & LNCaP & 104 \\
\hline PLGA & Doxorubicin & 230 & -45 & 80 & 5 & MDA-MB-23I & 42 \\
\hline PLGA & ICG and DOX & 170 & $\begin{array}{l}-9.9 \pm 0.4 \text { depending } \\
\text { on PLGA and PVA } \\
\text { concentration }\end{array}$ & $\begin{array}{l}44 \text { (ICG) } \\
74 \text { (DOX) }\end{array}$ & $\begin{array}{l}0.015 \text { (ICG) } \\
0.022 \text { (DOX) }\end{array}$ & & 107 \\
\hline PLGA & Curcumin & 45 & & 90 & & LNCaP, PC3, DU-I 45 & 109 \\
\hline PLGA & Curcumin & 76 & 0.06 & 89.5 & & A2780CP, MDA-MB-23I & 110 \\
\hline PLGA & Docetaxel & 217 & $-23.35 \pm 1.17$ & 87.99 & II.II & MCF-7 TAX30 & 114 \\
\hline PLGA & $\begin{array}{l}\text { Vincristine } \\
\text { Verapamil }\end{array}$ & 98 & $-0.75 \pm 0.12$ & $\begin{array}{l}68 \text { (VCR) } \\
80 \text { (VRP) }\end{array}$ & & MCF-7/ADR & 115 \\
\hline PLGA & Hypericin & $200-300$ & -7.9 & 15.4 & 0.2 & NuTu-19 & 116 \\
\hline PLGA & $\begin{array}{l}\text { Zinc (II) } \\
\text { Phthalocyanine }\end{array}$ & 200 & & 80 & & P388-DI & 152 \\
\hline PLGA & Paclitaxel & 182 & $\begin{array}{l}-3.45 \pm 0.58 \text { for } \\
\text { Pluronic }{ }^{\circledR}(\mathrm{P} 85)\end{array}$ & & & C6 rat glioma & 153 \\
\hline PLGA-d-a-TPGS & Docetaxel & 250 & -18.03 & 99.31 & 10 & HeLa & 122 \\
\hline $\begin{array}{l}\text { DMAB-modified } \\
\text { PLGA-TPGS }\end{array}$ & Docetaxel & 220 & 32.2 & 96 & 9.62 & MCF-7, Caco-2 & 154 \\
\hline PLGA & Paclitaxel & 240 & -35.6 & 66.21 & 5 & HT-29 & 155 \\
\hline PLGA & Paclitaxel & $200-300$ & & $34-62$ & & glioma $\mathrm{C} 6$ cells & 156 \\
\hline $\begin{array}{l}\text { PLGA ethylene } \\
\text { oxide fumarate }\end{array}$ & Paclitaxel & 190 & & $57-70$ & 3 & HCTII6 & 157 \\
\hline
\end{tabular}

Abbreviations: PLGA, polylactide-co-glycolide; DMAB, didodecyl dimethyl ammonium bromide; ICG, indocyanine green; DOX, doxorubicin; SCLC, small cell lung cancer; PVA, polyvinyl alcohol; VCR, Vincristine; VRP, Verapamil; EE, entrapment efficiency.

of docetaxel (Taxotere ${ }^{\circledR}$ ). ${ }^{102}$ The nanoprecipitation process has been applied for the formation of docetaxel-loaded nanoparticles. ${ }^{66,73}$ Cheng et al showed that limiting drugloading to $1 \%(\mathrm{w} / \mathrm{w})$ minimized particle aggregation and yielded docetaxel-loaded PLGA nanoparticles with narrower size distributions. ${ }^{66}$

\section{Cisplatin}

Mattheolabakis et al prepared cisplatin nanoparticles with an average size of 150-160 $\mathrm{nm}$ and an approximately $2 \%$ $\mathrm{w} / \mathrm{w}$ cisplatin content using a modified emulsification and solvent evaporation method. The cisplatin-loaded PLGAmonomethoxy (m)PEG nanoparticles appeared to be effective in delaying tumor growth in HT29 tumor-bearing mice with severe combined immune deficiency. The group of mice treated with cisplatin-loaded nanoparticles had a higher survival rate compared with the free cisplatin group. ${ }^{103}$ Cisplatin-loaded PLGA-mPEG nanoparticles also resulted in prolonged cisplatin residence time in the systemic circulation when used in mice with prostate cancer. ${ }^{104}$

\section{Doxorubicin}

Betancourt et al formulated nanoparticles by nanoprecipitation of acid-ended PLGA to control the release of doxorubicin in a pH-dependent manner and deliver high loads of active drug to an MDA-MB-231 breast cancer cell line. The $\mathrm{pH}-$ dependent release behavior could be a result of accelerated degradation of the polymer and decreasing ionic interaction between the drug and the polymer at an acidic $\mathrm{pH} .{ }^{42}$

Another approach to improve the efficacy and selectivity of cancer treatment is the application of hyperthermia in combination with traditional cancer therapeutics, such as radiation therapy and chemotherapy. ${ }^{105,106}$ Hyperthermia makes some cancer cells more sensitive to radiation and can also enhance the effect of certain anticancer drugs, ${ }^{106}$ thus allowing the use of decreased chemotherapy doses. 
Indocyanine green is an optical tracer that can generate heat by absorbing near-infrared light. The significance of the Manchanda et al study is the synthesis of multifunctional PLGA nanoparticles and the incorporation of drugs with different physical properties (indocyanine green being amphiphilic and doxorubicin being hydrophobic). These indocyanine green-doxorubicin nanoparticles have potential applications as drug delivery systems for combined chemotherapy and localized hyperthermia. ${ }^{107}$

\section{Curcumin}

Curcumin has been used in traditional medicine for many centuries in India and China. ${ }^{108}$ It is chemically diferuloylmethane, a yellow polyphenol extracted from the rhizomes of turmeric (Curcuma longa). The only factor that limits the use of free curcumin for cancer therapy is its poor solubility in water, which in turn limits its systemic bioavailability when administered orally. Mukerjee and Vishwanatha formulated curcumin-loaded PLGA nanoparticles, and suggested that a nanoparticle-based formulation of curcumin has high potential as adjuvant therapy in prostate cancer. ${ }^{109}$

Another study demonstrated that curcumin encapsulation in PLGA nanoparticles employing a nanoprecipitation approach in the presence of polyvinyl alcohol and poly L-lysine stabilizers not only produced a very stable nanoformulation but also enhanced cellular drug uptake and retention, as well as sustained release of curcumin. The optimized nanoparticle formulation has shown a greater inhibitory effect on the growth of metastatic cancer (A2780CP and MDA-MB-231) cells than free curcumin. ${ }^{110}$

\section{Multidrug resistance}

A major barrier to successful cancer treatment is multidrug resistance. It has been reported that most patients, even those who are initially responsive, acquire a multidrug-resistant phenotype, and some patients show multidrug-resistance even at their first treatment. In metastatic breast cancer, the development of a multidrug-resistant phenotype is primarily responsible for insensitivity to a new drug. ${ }^{111}$ Therefore, resistance to chemotherapeutic agents is the major challenge in the treatment of breast cancer. It has been shown that nanoparticles can reduce the multidrug-resistance characterizing many anticancer drugs via a drug internalization mechanism mediated by P-glycoprotein, thereby reducing its efflux from cells. ${ }^{112,113}$

Yan et al showed that the cytotoxicity of a PLGApoloxamer188 nanoparticle blend containing docetaxel against MCF-7 TAX30 cells was higher than that of the free drug, indicating that poloxamer 188 could enhance the ability of PLGA nanoparticles to overcome multidrug resistance. A docetaxel-loaded PLGA-poloxamer188 nanoparticle formulation has been developed to overcome multidrug resistance in a docetaxel-resistant human breast cancer cell line (MCF-7 TAX30). ${ }^{114}$

Multidrug resistance may be treated using a combination of entrapped cytotoxic drugs and chemosensitizers. To optimize the effectiveness of this approach, Song et al prepared PLGA nanoparticle formulations capable of delivering vincristine (a cytotoxic drug) and verapamil (a chemosensitizer), or a combination of these agents by combining the oil-in-water emulsion solvent evaporation and salting-out methods. PLGA nanoparticles showed moderate multidrug-resistance reversal in MCF-7/ADR cells resistant to vincristine. Coencapsulation of an anticancer drug and chemosensitizer may cause lower drug toxicity and fewer drug-drug interactions. Therefore, PLGA nanoparticles simultaneously loaded with an anticancer drug and a chemosensitizer may potentially be a very promising formulation for treatment of drug-resistant cancers in vivo. ${ }^{115}$

\section{Photodynamic therapy}

Photodynamic therapy combines a photosensitizing agent with a specific type of light to kill cancer cells. This technique is minimally invasive, with great potential in both malignant and premalignant conditions. Photodynamic therapy requires the presence of a photosensitizing agent, oxygen, and light of a specific wavelength matching the absorption characteristics of the photosensitizer agent. Administration of the photosensitizer is followed by illumination of the tumor with visible light in a wavelength range matching the absorption spectrum of the photosensitizer agent.

Hypericin, a natural photosensitizer extracted from Hypericum perforatum, is a potential tool for the detection and treatment of ovarian and other cancers. Due to its hydrophobicity, systemic administration of hypericin is problematic. A photodynamic approach has been suggested by Zeisser-Labou et al to improve the diagnosis and treatment of ovarian cancer. ${ }^{116}$ This group used polymeric nanoparticles of polylactic acid or PLGA as a drug delivery system, and compared the in vitro photoactivity of the nanoparticles and that of the free drug using the NuTu-19 ovarian cancer cell model derived from Fischer 344 rats. Their studies showed that hypericin-loaded nanoparticles exhibited higher photoactivity than did the free drug, and increasing light dose and cell incubation time enhanced their activity.

Ricci-Junior and Marchetti have prepared, characterized, and assayed the photocytotoxicity of PLGA nanoparticles 
containing zinc (II) phthalocyanine for use in photodynamic therapy. These nanoparticles maintained their photophysical behavior after the encapsulation process. ${ }^{51}$

\section{Surface modification of PLGA nanoparticles}

Polymeric nanoparticles have been characterized by their morphology and polymer composition. The drug molecule is either conjugated to the surface of the nanoparticles or entrapped and protected inside the core. The unique sizes of these nanoparticles are amenable to surface functionalization or modification to achieve any desired characteristics. This has been achieved by various methods to increase drug retention time in blood, to reduce nonspecific distribution, and to target tissues or specific cell surface antigens with targeting ligands, such as peptides, aptamers, antibodies, and small molecules. ${ }^{117}$

Opson in proteins present in the bloodstream quickly bind to conventional nonstealth nanoparticles, allowing macrophages of the molecular phagocytic system to recognize and remove these drug delivery devices before they can exert their therapeutic effects. ${ }^{118}$ Opsonization of injected particles by antibodies in the circulation, attachment of opsonized particles to macrophages, and subsequent internalization by phagocytosis are important steps in the clearance of particles by the molecular phagocytic system.

Different materials are used for the preparation of nanoparticles, leading to distinct surface properties. Surface modification of nanoparticles is important for escaping the body's natural defense systems when transporting drugs to the bloodstream. ${ }^{78}$ Unless nanoparticles are modeled to escape recognition by the molecular phagocytic system, they will be eliminated from the body. A long circulation time increases the probability that the nanoparticles will reach their target. Nanostructures smaller than $100 \mathrm{~nm}$ with a hydrophilic surface have the greatest ability to evade the molecular phagocytic system. ${ }^{30}$

To increase circulation time, the particles can be coated with molecules that provide a hydrophilic protective layer, such as PEG, polyvinylpyrrolidone, human serum albumin, poloxamers, polysorbate 80 , polysorbate 20 , vitamin $\mathrm{E}$ TPGS, polysaccharides (eg, dextran) and different types of copolymers. ${ }^{119}$ Here we discuss three of the more important materials used for surface modification of PLGA nanoparticles.

\section{Polyethylene glycol}

Adsorption or grafting of PEG to the surface of nanoparticles is the preferred method for shielding nanoparticles from the molecular phagocytic system..$^{59,103,104}$ Addition of PEG or PEG-containing copolymers to the nanoparticle surface results in an increase of half-life in the blood circulation by several orders of magnitude. This method creates a protective hydrophilic layer around the nanoparticles that is able to repel the adsorption of proteins via steric repulsion forces, thereby blocking and delaying the first step in the opsonization process. ${ }^{118}$

PEG is a hydrophilic nonionic polymer that has been shown to have excellent biocompatibility. PEG coating on the surface of polymers reduces interaction between the nanoparticles and digestive enzymes, and increases uptake of the encapsulated drug in the bloodstream and lymphatic tissue. ${ }^{120}$

PLGA nanoparticles have been surface-modified with PEG in an attempt to protect them from the reticuloendothelial system. ${ }^{59,103,104}$ Avgoustakis et al considered the feasibility of using long circulating PLGA-mPEG nanoparticles as carriers for passive targeting of cisplatin to tumors. They showed that intravenous administration of PLGA-mPEG nanoparticles loaded with cisplatin in mice resulted in a prolonged residence time of cisplatin in the systemic circulation. ${ }^{65}$

\section{Vitamin ETPGS}

TPGS is a widely used form of vitamin $\mathrm{E}$ that has been used as a solubilizer, an emulsifier, and a vehicle in drug delivery formulations. TPGS has been used as an emulsifier for producing nanoparticles containing hydrophobic drugs and for improving encapsulation efficiency, drug loading, and the release profile of nanoparticles. ${ }^{81}$ Surface modification by TPGS increases adhesion of the nanoparticles to the tumor cell surface. ${ }^{78,121}$ TPGS has also been blended with PLGA for the preparation of nanoparticles. ${ }^{28}$ TPGS increases adhesion of PLGA nanoparticles to cells and the hemodynamic properties of the nanoparticles.

Ma et al synthesized PLGA-TPGS copolymers as nanoparticle carriers for small molecular weight anticancer drugs, using docetaxel as a model drug. In vitro cellular uptake of these nanoparticles was investigated by confocal laser scanning microscopy, which demonstrated that fluorescent PLGA-TPGS nanoparticles could be internalized by HeLa, a human cervical carcinoma cell line. Random PLGA-TPGS copolymers could act as a novel and potential biocompatible polymeric matrix material applicable to nanoparticle-based drug delivery systems for cancer chemotherapy. ${ }^{122}$

\section{Pluronic $^{\circledR}$}

Pluronic block copolymers consist of ethylene oxide and propylene oxide blocks arranged in a basic A-B-A structure, 
ie, ethylene oxide-propylene oxide-ethylene oxide. The incorporation of drugs into the core of the micelles formed by Pluronic results in increased solubility, metabolic stability, and a longer circulation time for the drug. ${ }^{123}$

Kabanov et al demonstrated that Pluronics P85, F68, and L61 reduced the respiration rate of both drug-sensitive cells and the molecular phagocytic system, resulted in hypersensitivity to chemotherapy. Cells often achieve their drug resistance via the efflux of drugs through energy-dependent transporters, so reduction in respiration impairs this mechanism. ${ }^{123}$

Shah et al formulated paclitaxel-PLGA nanoparticles surface-modified with Pluronic P85 for inhibition of P-glycoprotein. This study demonstrated the feasibility of targeting nanoparticles to specific cancer tumor cells, cell internalization, and successful overcoming of the P-glycoprotein-mediated paclitaxel efflux mechanism, and demonstrated a significant increase in uptake of Pluronic P85-coated nanoparticles. ${ }^{124}$

\section{PLGA nanoparticle targeting strategies}

In the process of killing cancer cells, chemotherapeutic agents also damage healthy tissues, leading to systemic toxicity and adverse side effects. Thus, an important step in improving treatment regimes is achieving more effective targeting of anticancer drugs to tumor tissues. Therefore, the need to develop novel cancer therapies and drug delivery strategies specifically targeted to tumor cells continues to be a major focus for scientists. Nanoparticle systems offer major improvements in therapeutics through site specificity, an ability to evade multidrug resistance, and efficient delivery of anticancer agents. ${ }^{125}$

Ideally, drug delivery systems should improve the stability, absorption, and therapeutic action of the drug within the target tissue and permit controlled release of the drug. Targeting cancer cells using nanoparticles loaded with anticancer agents is a promising strategy that could overcome these challenges. Drug targeting can be achieved by taking advantage of the distinct pathophysiological features of tumor tissue (ie, passive targeting) or by actively targeting the drug carrier using target-specific ligands (ie, active targeting). ${ }^{126,127}$

\section{Passive targeting}

Passive targeting exploits the anatomical differences between normal tissue and tumor tissue to deliver drugs to the desired site. The vasculature in tumor tissues is very different from that in normal tissues. It is more heterogeneous in distribution, larger in size, has higher vascular density, and is more permeable and leaky, with gap sizes of $100 \mathrm{~nm}$ to $2 \mu \mathrm{m}$ depending on the tumor type, unlike the tight endothelium of normal blood vessels. In addition, extensive production of vascular mediators, including bradykinins, nitric oxide, vascular endothelial growth factor, and prostaglandins, facilitates extravasation. This, coupled with impaired lymphatic drainage of macromolecules in solid tumors, allows enhanced accumulation and retention of high molecular weight drugs in solid tumors. This is popularly known as the "enhanced permeation and retention effect", that allows extravasation of circulating polymeric nanoparticles within the tumor interstitium and also increases concentrations of the chemotherapeutic agent within the tumor tissue (Figure 4). ${ }^{125-127}$ It should be mentioned that nanoparticles within the size range of 60-400 nm are effective for this type of targeting. ${ }^{128,129}$

These are three in vivo studies based on the permeation and retention effect. Bhardwaj et al formulated PLGApaclitaxel nanoparticles stabilized with DMAB and administered orally to female Sprague Dawley rats. ${ }^{101}$ Paclitaxel nanoparticles administered orally were as effective as paclitaxel given intravenously with Cremophor $^{\circledR}$ EL at a $50 \%$ reduced dose, and was significantly better than oral paclitaxel in the Cremophor EL group. This in vivo proofof-concept study provides encouraging evidence of the value of nanoparticulate anticancer formulations, and highlights the anticancer efficacy of paclitaxel when incorporated into nanoparticles. The nanoparticle formulation was as effective as the drug used alone, but at half the dose. The average tumor weight measured after paclitaxel orally administered in Cremophor was roughly three-fold higher than after the nanoparticulate formulation. ${ }^{101}$

Danhier et al formulated Cremophor EL-free paclitaxelloaded PEGylated PLGA-based nanoparticles by a nanoprecipitation method. In vivo tumor growth inhibition by the paclitaxel-loaded nanoparticles was then investigated in transplantable liver tumor-bearing mice. Paclitaxel was shown to reach the tumor site via the enhanced permeation and retention effect and maintain an effective therapeutic concentration. ${ }^{59}$

In another study, Mattheolabakis et al investigated tolerance of BALB/c mice to different doses of blank and cisplatinloaded PLGA-mPEG nanoparticles, and the in vivo anticancer activity of cisplatin-loaded PLGA-mPEG nanoparticles in mice with severe combined immune deficiency bearing HT29 colon adenocarcinoma. By in vivo antitumor activity assay, the PLGA-mPEG-cisplatin nanoparticles appeared to reduce tumor growth in mice with severe combined immune deficiency and HT29 xenografts, and these mice had higher survival rates than those treated with free cisplatin. ${ }^{103}$ 


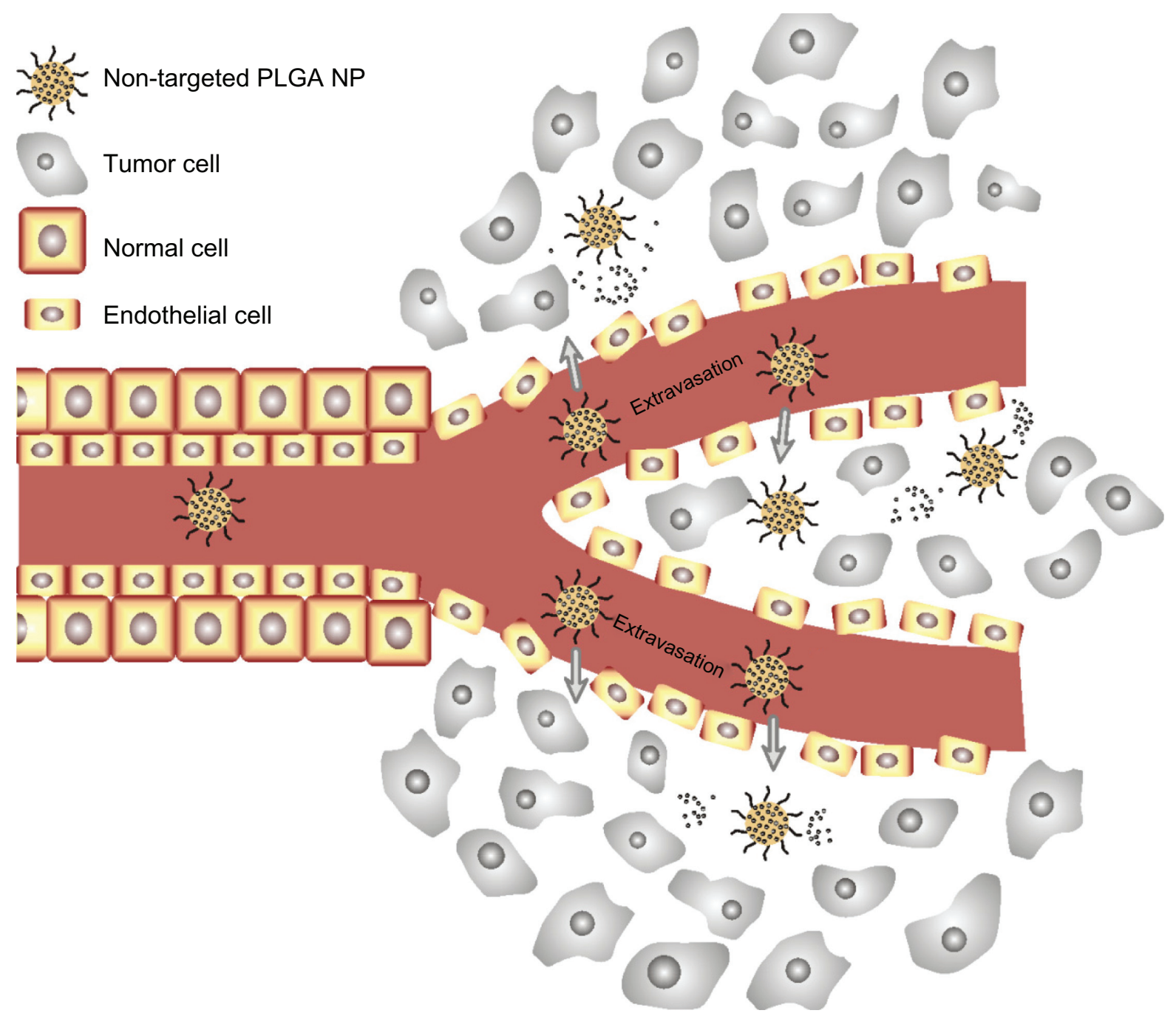

Figure 4 Enhanced permeability and retention effect. Passive tissue targeting is achieved by extravasation of nanoparticles through increased permeability of the tumor vasculature and ineffective lymphatic drainage.

Abbreviations: PLGA, polylactide-co-glycolide; NP, nanoparticles.

\section{Active targeting}

Active targeting involves the use of peripherally attached targeting moieties for enhanced delivery of nanoparticle systems (Figure 5). Active targeting to the tumor can be achieved by molecular recognition of cancer cells either via ligand-receptor or antigen-antibody interactions, or by targeting through aptamers, that allow preferential accumulation of the drug in tumor tissue, within individual cancer cells or specific molecules in cancer cells. Long circulation times will allow for effective transport of the nanoparticles to the tumor site through the enhanced permeation and retention effect, and the targeting molecule can increase endocytosis of the nanoparticles. The success of drug targeting depends on the selection of the targeting agent, which should be abundant, have high affinity and specificity of binding to cell surface receptors, and should be well-suited to chemical modification by conjugation.
The receptors and their surface-bound antigens may be expressed only in diseased cells or may exhibit a differentially higher expression in diseased cells as compared with normal cells. Thus, the tumor endothelium provides many targets for cancer therapy (Figure 6). ${ }^{127,130}$ Here we discuss the three main categories of targeting moieties used for PLGA nanoparticles. These targeted nanoparticles are also shown in Table 3.

\section{Ligand-receptor interaction}

The lectin-carbohydrate interaction is highly specific, and can be exploited for the development of nanoparticles containing carbohydrate moieties that are directed to certain lectins, or vice versa. Several lectins have been found to possess anticancer properties, and are used as therapeutic agents, preferentially binding to cancer cell membranes or their receptors, causing cytotoxicity, apoptosis, and inhibition of tumor growth. ${ }^{125}$ 


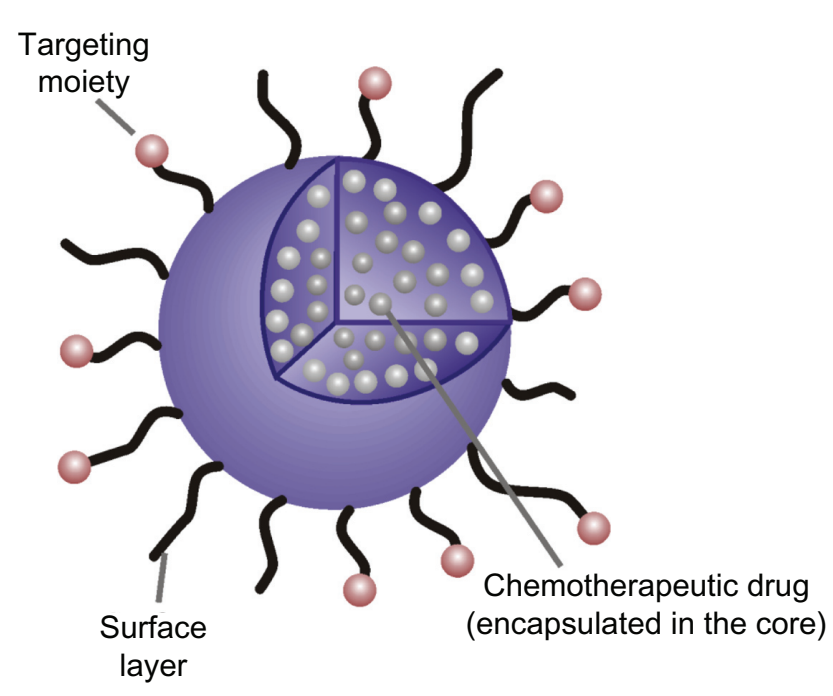

Figure $\mathbf{5}$ Targeted polylactide-co-glycolide nanoparticle carrying the chemotherapeutic drug.

Mo and Lym developed novel lectin-conjugated isopropyl myristate-incorporating PLGA nanoparticles for local delivery of paclitaxel to the lungs. These nanoparticles had superior in vitro cytotoxicity against A549 and H1299 cells as compared with paclitaxel-loaded nanoparticles without isopropyl myristate or wheat germ agglutinin, or paclitaxelloaded nanoparticles with only isopropyl myristate or wheat germ agglutinin. Thus, their studies showed that these nanoparticles exhibited a stronger cytotoxic effect because of more efficient cellular uptake via wheat germ agglutinin receptormediated endocytosis and isopropyl myristate-facilitated release of paclitaxel from the nanoparticles. ${ }^{52}$

There is broad interest in the development of nanoparticles carrying carbohydrates, such as sialic acids, on their surface. Macromolecular compounds containing these carbohydrates show an antirecognition effect, exert an antiviral effect, and are also able to be recognized by the cell surface of some cancer cell types. ${ }^{131}$ Bondioli et al used two different approaches to obtain polymeric PLGA nanoparticles surface-decorated with sialic acid $\mathrm{N}$-acetylneuraminic acid (Neu5Ac). The first strategy used is based on derivatization of PLGA with the thioderivative of Neu5Ac as the starting material for the preparation of nanoparticles, and the second strategy is based on the synthesis of compounds potentially able to insert their lipophilic moiety into nonderivatized PLGA nanoparticles during their preparation and display their hydrophilic moiety (Neu5Ac) on their surface. ${ }^{131}$

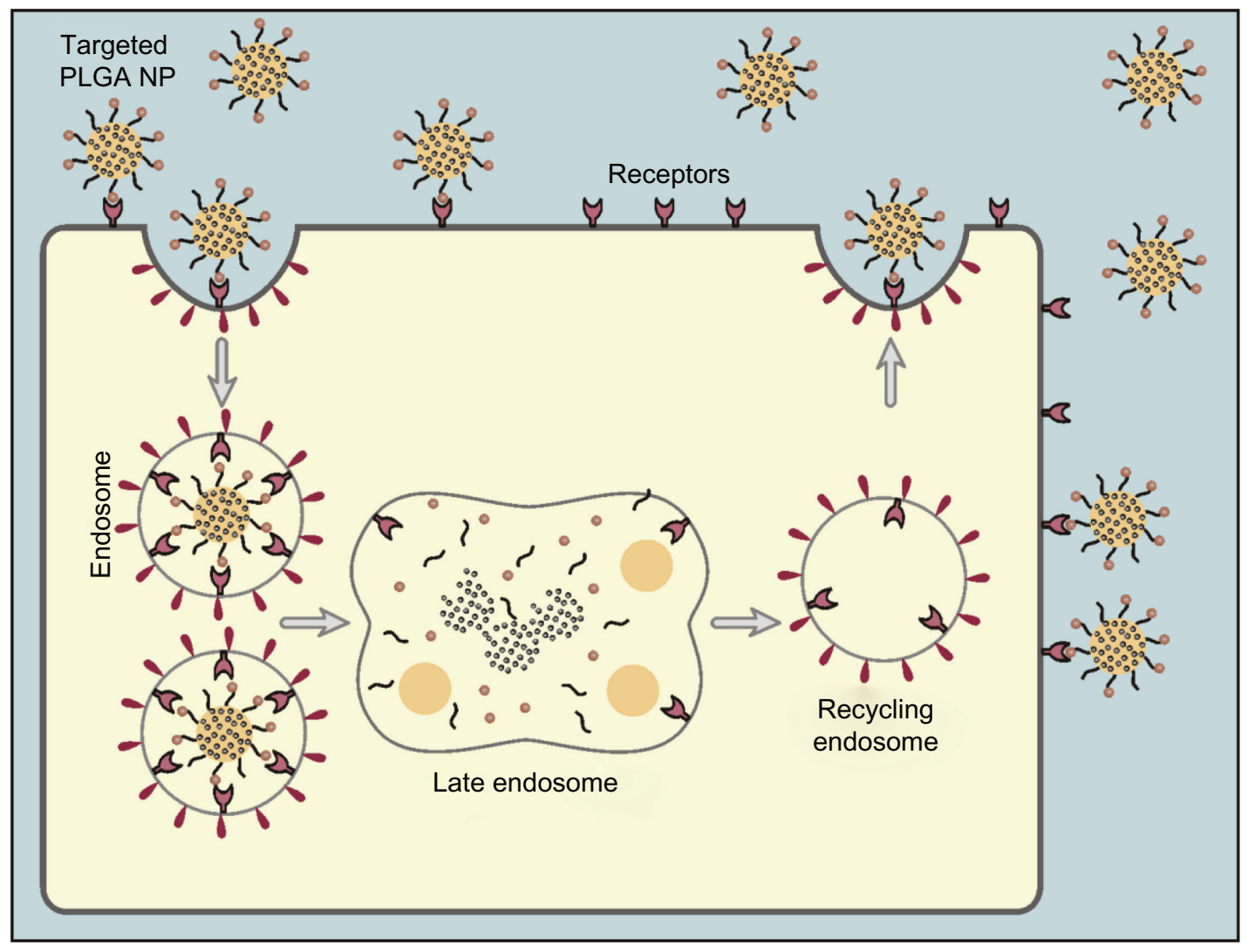

Figure 6 Internalization of targeted polylactide-co-glycolide nanoparticles via receptor-mediated endocytosis. Since specific receptors are overexpressed on tumor cells, the nanoparticles are selectively uptaken by the tumor cells via receptor-ligand interaction.

Abbreviations: PLGA, polylactide-co-glycolide; NP, nanoparticles. 
Table 3 Summary of targeted polylactide-co-glycolide nanoparticles

\begin{tabular}{|c|c|c|c|c|}
\hline Layer & Targeting moiety & Anticancer drug & Size (nm) & Reference \\
\hline & Lectin & Paclitaxel & $330.7 \pm 2.9$ & 52 \\
\hline & Sialic acid $\mathrm{N}$-acetylneuraminic acid (Neu5AC) & & $\sim 70$ & $|3|$ \\
\hline Egg & Transferrin & Aromatase inhibitor & $170.3 \pm 7.6$ & 132 \\
\hline \multicolumn{5}{|l|}{ phosphatidylcholine } \\
\hline and DOPE & & $(7 \alpha-A P T A D D)$ & & \\
\hline Vitamin E TPGS & Folate & Doxorubicin & $\sim 350$ & 136 \\
\hline PEG & Folate & Doxorubicin & $104 \pm 11.5$ & 135 \\
\hline PEG & Folate & Docetaxel & $216 \pm 18$ & 50 \\
\hline PEG & Biotin & Paclitaxel and tariquidar/siRNA & $\sim 240$ & 143,144 \\
\hline \multirow[t]{2}{*}{ Polylysine } & SM5-I single chain antibody & Paclitaxel & $129 \pm 5.2$ & 145 \\
\hline & $\begin{array}{l}\text { Mab against soluble membrane proteins } \\
\text { of MCF-7 }\end{array}$ & & $320-360$ & 146 \\
\hline PEG & cRGD & Doxorubicin & $423 \pm 16.6$ & 133 \\
\hline \multirow[t]{4}{*}{ PEG } & RGD and RGD-peptidomimetic & Paclitaxel & $138 \pm 3,146 \pm 2$ & 134 \\
\hline & Epidermal growth factor receptor antibody & Rapamycin & $\sim 287$ & 147 \\
\hline & Trastuzumab & Paclitaxel & $3 \mid 2.3 \pm 8.2$ & 148 \\
\hline & Anti-HER 2 Fab' & $\begin{array}{l}\text { Pseudomonas exotoxin } \\
\text { (PE38 KDEL) }\end{array}$ & $124.2 \pm 21.2$ & 149 \\
\hline PEG & A I0 PSMA aptamer & Docetaxel & $\sim 180$ & 150 \\
\hline PEG & A I0 PSMA aptamer & Cisplatin & $\sim 140$ & 151 \\
\hline
\end{tabular}

Abbreviations: PSMA, prostate-specific membrane antigen; PEG, polyethylene glycol; Mab, monoclonal antibody; RGD, arginine-glycine-aspartic acid sequence; DOPE, dioleoyl phosphatidylethanolamine; vitamin E TGPS, $\alpha$-tocopheryl polyethylene glycol 1000 succinate.

Transferrin receptors are overexpressed by $2-10$-fold in most tumor cells, and thus, transferrin and/or transferrin antibodies may be used for targeting drugs to tumor cells. ${ }^{125}$ Zheng et al synthesized transferrin-conjugated lipid-coated PLGA nanoparticles carrying the aromatase inhibitor, 7-(4-amino) phenylthio-1, 4-androstadiene-3, 17-dione. The aromatase inhibition activity of the nanoparticles was evaluated in a SKBR-3 breast cancer cell line. The $\mathrm{IC}_{50}$ value of the nanoparticles incorporating transferrin ranged from 0.77 to $1.21 \mathrm{nM}$, and the $\mathrm{IC}_{50}$ value of the nanoparticles ranged from 1.90 to $3.41 \mathrm{nM}(\mathrm{n}=3)$. These results suggest that the aromatase inhibition activity of the transferrin nanoparticles was enhanced relative to that of the nontargeted nanoparticles, which was attributable to transferrin receptor-mediated uptake. ${ }^{132}$

The $\alpha_{v} \beta_{3}$ integrin is an endothelial cell receptor for extracellular matrix proteins harboring the arginine-glycine-aspartic acid (RGD) sequence. ${ }^{126}$ Wang et al conjugated doxorubicin to PLGA, and the nanoparticle surfaces were then linked with PEG and the RGD peptides to achieve both passive and active targeting functions. The nanoparticle targeting ability was enhanced via strong affinity to various integrin-expressing cancer cells, and much less affinity to low integrin-expressing cancer cells. ${ }^{133}$ Danhier et al showed that PEGylated PLGAbased nanoparticles grafted with the RGD peptide or an RGD peptidomimetic, targeted the tumor endothelium and would enhance the antitumor efficacy of paclitaxel. They observed that RGD-grafted nanoparticles were more associated with human umbilical vein endothelial cells in vitro by binding to $\alpha_{\mathrm{v}} \beta_{3}$ integrin than were nontargeted nanoparticles, and they also demonstrated the targeting of RGD and RGD peptidomimetic-grafted nanoparticles to tumor vessels, as well as effective retardation of transplantable liver tumor growth and prolonged survival times in mice treated by paclitaxel-loaded RGD nanoparticles when compared with nontargeted nanoparticles. ${ }^{134}$

The folate receptor is a highly specific tumor marker that is overexpressed in many human cancers. In addition, this receptor is absent in most normal tissues, so is frequently exploited for drug-targeting purposes. With the proper design, folate-drug conjugates display high-affinity properties which enable them to bind rapidly to the folate receptor and become internalized via an endocytic process. ${ }^{125}$

Yoo and Park prepared biodegradable polymeric micelles self-assembled from a diblock copolymer of PLGA and PEG to achieve delivery of doxorubicin to the folate receptor. They showed higher cytotoxicity to the folate-conjugated mixed micelles than for free doxorubicin, suggesting that folate receptor-mediated endocytosis of micelles plays an important role in transporting an increased amount of doxorubicin into cancer cells. In addition, in vivo animal experiments using a nude mouse xenograft model demonstrated that, when systemically administered, tumor volume was significantly reduced. ${ }^{135}$

In another study, Zhang et al synthesized doxorubicinloaded folate-decorated PLGA-vitamin E TPGS nanoparticles for targeted chemotherapy to folate receptor-rich tumors. 
Their research showed that the TPGS-folate uptake was 1.5 and 1.7 times higher in MCF-7 and C6 cells, respectively, as compared with nanoparticles with no TPGS-folate component after 30 minutes of incubation. ${ }^{136}$

The authors of the present study produced docetaxel nanoparticles by using PLGA-PEG-folate conjugates for folate receptor-targeted anticancer delivery. The folate receptor-targeted nanoparticles showed greater intracellular uptake in folate receptor-positive cancer cells (SKOV3) in comparison with the nontargeted nanoparticles, indicating that a folate receptor-mediated endocytosis mechanism could have a role in the cellular uptake of nanoparticles. ${ }^{50}$ In another study, the same research group studied the use of PLGA-PEG-folate nanoparticles containing SN-38 (7-ethyl-10-hydroxy camptothecin). These folate receptortargeted nanoparticles showed greater cytotoxicity against cancer cells than nontargeted SN-38 nanoparticles.

Biotin is an essential micronutrient for normal cellular functions (eg, biosynthesis of fatty acids, gluconeogenesis), growth, and development. Humans and other mammals cannot synthesize biotin and thus must obtain it from exogenous sources via intestinal absorption. Rapidly dividing cells, such as cancer cells, have a voracious appetite for certain vitamins, including biotin, vitamin B12, and folate. Biotin levels have been found to be significantly higher in some cancer cells compared with normal tissue. ${ }^{137}$ Interestingly, tumor cell lines, including ovarian and colorectal, which overexpress receptors involved in folate or vitamin B12 uptake also show overexpression of biotin receptors. ${ }^{138}$ Accordingly, several research groups have tested different biotinylated chemotherapeutic agents for cancer cell-specific drug delivery. ${ }^{139-142}$

Patil et al investigated simultaneous targeted delivery of paclitaxel with tariquidar (a third-generation P-glycoprotein modulator) using PLGA nanoparticles to overcome tumor drug resistance. Nanoparticles were surface-functionalized with biotin for active tumor targeting. ${ }^{143}$ In the same study, this group used small interfering RNA instead of tariquidar to silence expression of the P-glycoprotein efflux transporter in Balb/c mice bearing JC (mammary adenocarcinoma) tumors. Growth in tumor volume and survival were monitored on a regular basis. Biotin-conjugated nanoparticles demonstrated more tumor growth inhibition than the nontargeted nanoparticles. ${ }^{144}$

\section{Antigen-antibody interaction}

In recent years, overexpressing cancer-specific antigens have become an important tool in developing different delivery technologies for cancer treatment. The advent of monoclonal antibody technology in the 1970s and the development of genetically engineered derivatives in the 1980s, along with technological advances in the bulk production of monoclonal antibodies, have led to a number of clinical studies evaluating the efficacy of cancer-specific monoclonal antibodies in targeted drug delivery systems. The overexpression of receptors and antigens in human cancers also helps efficient uptake via receptor-mediated endocytosis. Moreover, due to their transformed nature, tumor cells overexpress many new proteins in comparison with normal cells, and these markers may be exploited for active drug targeting. ${ }^{125}$ Kou et al developed paclitaxel-loaded PLGA nanoparticles coated with cationic SM5-1 single-chain antibody. Nonradioactive cell proliferation assay demonstrated that targeted nanoparticles had significantly better in vitro cytotoxicity against Ch-hep-3 human hepatocellular cancer cells than nontargeted paclitaxel-loaded PLGAnanoparticles. ${ }^{145}$

Kocbek et al prepared PLGA immunonanoparticles for targeting invasive epithelial breast tumor cells. The monoclonal antibody was prepared against soluble membrane proteins of MCF-7 human invasive ductal breast carcinoma and was attached to the nanoparticle surface either covalently or noncovalently. These nanoparticles were more likely to attach to the targeted cells than the noncoated nanoparticles. In coculture of MCF-10A neoT and Caco-2 cells, immunonanoparticles entered only MCF-10A neoT cells, while noncoated nanoparticles were taken up by both cell types, indicating specific targeting by the immunonanoparticles. ${ }^{146}$

The human epidermal receptor (HER) family of receptor tyrosine kinases offers two highly upregulated targets on tumor cell surfaces. These receptor tyrosine kinases, epidermal growth factor receptor and human epidermal receptor-2 (HER2), are known to mediate a cell signaling pathway for growth and proliferation in response to binding of the growth factor ligand. ${ }^{125}$ Achraya et al prepared and characterized rapamycin-loaded PLGA nanoparticles so that their surfaces were modified with antibodies to the epidermal growth factor receptor, highly expressed on breast cancer cells, and improved the cytotoxicity of nanoparticles in a malignant MCF7 breast cancer cell line. $\mathrm{IC}_{50}$ doses, determined by MTT assay, showed superior antiproliferative activity of antibodyconjugated rapamycin-loaded nanoparticles compared with the unconjugated nanoparticles and native rapamycin due to higher cellular uptake by malignant breast cancer cells. The molecular basis of apoptosis, studied by Western blotting, revealed the involvement of a cytoplasmic protein in activating the programmed cell death pathway. Thus, it was concluded that epidermal growth factor receptor antibodyconjugated rapamycin-loaded nanoparticles provide efficient and targeted delivery of anticancer drugs. ${ }^{147}$ 
Trastuzumab, approved by the Food and Drug Administration, is amonoclonal antibody designed to antagonize HER2 function, and has been used as a targeting moiety in various nanoparticle systems. ${ }^{126}$ Sun et al investigated a nanoparticle formulation containing PLGA-montmorillonite and trastuzumab for targeted breast cancer chemotherapy, with paclitaxel as a model anticancer drug. The in vitro drug release from this nanoparticle formulation showed a biphasic drug-release pattern, with a moderate initial burst release followed by a sustained release profile. ${ }^{148}$ Gao et al developed Pseudomonas exotoxin (PE38KDEL)-loaded PLGA nanoparticles conjugated with Fab' fragments (rhuMAbHER2) from a humanized anti-HER2 monoclonal antibody (PE-NP-HER). Compared with nontargeted nanoparticles lacking anti-HER2 Fab', PE-NP-HER specifically bound to and was sequentially internalized into HER2-overexpressing breast cancer cells, which resulted in significant cytotoxicity in vitro. Notably, PE-NP-HER was of low immunogenicity in the development of anti-PE38KDEL-neutralizing antibodies, and was less susceptible to inactivation by anti-PE38KDEL antibodies compared with PE-HER. ${ }^{149}$

\section{Aptamer-mediated targeting}

Aptamers are DNA or RNA oligonucleotides (short DNA or RNA oligonucleotide ligands) capable of binding to target antigens with high affinity and specificity, and are analogous to antibodies. ${ }^{125}$ The group led by Farokhzad and Langer ${ }^{150,151}$ investigated the targeting potential of aptamers specific to the extracellular domain of the prostate-specific membrane antigen (PSMA). Farokhzad et al developed $180 \mathrm{~nm}$ docetaxel-encapsulated nanoparticles using a PLGAblock-PEG copolymer surface-functionalized with the A10 20-fluoropyrimidine RNA aptamers that recognize PSMA. Their results showed significant enhancement of the cellular toxicity of the functionalized nanoparticles in vitro as compared with the nontargeted nanoparticles lacking the PSMA aptamer. In addition, after a single intratumoral injection of docetaxel-aptamer bioconjugate nanoparticles, complete tumor reduction was observed in five of seven $\mathrm{LNCaP}$ xenograft nude mice, and $100 \%$ survival was observed as compared with mice treated with docetaxel nanoparticles alone. They also studied the biodistribution of the nanoparticles in aLNCaP (PSMA+) xenograft mouse model of prostate cancer. Surface functionalization of the nanoparticles with A10 PSMA aptamer significantly enhanced (3.77-fold increase at 24 hours in nanoparticle aptamer of injected dose per gram of tissue) the delivery of nanoparticles to tumors versus equivalent nanoparticles lacking the A10 PSMA aptamer. ${ }^{150}$

In another study, Dhar et al also used PLGA-b-PEG nanoparticles with PMSA-targeting aptamers on the surface as a vehicle for the platinum (IV) compound, c, t, c-[Pt(NH3) (2) $(\mathrm{O} 2 \mathrm{CCH} 2 \mathrm{CH} 2 \mathrm{CH} 2 \mathrm{CH} 2 \mathrm{CH} 3)(2) \mathrm{Cl}-2]$, as a strategy to deliver cisplatin to prostate cancer cells. A comparison between the cytotoxic activities of Pt(IV)-encapsulated PLGA-b-PEG nanoparticles with the PSMA aptamer on the surface (Pt-NP-Apt), cisplatin, and the nontargeted Pt(IV)encapsulated nanoparticles against human PSMA overexpressing $\mathrm{LNCaP}$ and PSMA(-) PC3 cancer cells revealed significant differences. The effectiveness of PSMA-targeted Pt-NP-Apt nanoparticles against the PSMA (+) LNCaP cells was significantly greater than that of free cisplatin. ${ }^{151}$

\section{Conclusion}

Current polymeric nanocarrier technologies have demonstrated remarkable advantages for cancer therapy when compared with conventional drugs. Among the polymers utilized to date, PLGA is very promising for the preparation of novel anticancer drug delivery systems due to its desirable characteristics, including good biodegradability and biocompatibility. PLGA nanoparticles can achieve tumortargeted drug delivery via passive targeting based on the enhanced permeation and retention effect, or active targeting by an appropriate ligand, which improves antitumor efficacy and reduces toxicity on healthy tissues. For further advancement, it will be necessary to focus more research attention on the pharmacokinetics, biodistribution, and safety of these novel drug delivery systems.

Development of multifunctional PLGA nanoparticles containing specific ligands for active targeting, and multiple drugs for synergistic anticancer effects and overcoming drug resistance, will provide a versatile and straightforward approach to improving chemotherapy. Combined therapeutic and diagnostic (theranostic) nanoparticles will be another potential future direction. In this case, theranostic PLGA nanoparticles will be detected in tumors by using a diagnostic agent. These nanoparticles can modulate their responses based on changes in the environment. When imaging shows maximum nanoparticle accumulation in tumor tissue, physical sources, such as light or heat, can be applied to modify nanoparticle drug-releasing activity.

Lastly, despite significant progress so far, a large gap between the cost of preparing PLGA nanoparticles and that of conventional delivery systems is seen as an impediment to their commercial application. Until now, most of the 
methods reported for preparation and surface modification of PLGA nanoparticles have involved small batches. Scale-up to large production volumes will certainly introduce additional challenges. As a result, the preparation process for PLGA nanoparticles needs to be further developed to achieve the reproducibility and scalability necessary in the marketplace.

\section{Disclosure}

The authors report no conflicts of interest in this work.

\section{References}

1. Allémann E, Gurny R, Doelker E. Drug-loaded nanoparticles - preparation methods and drug targeting issues. Eur J Pharm Biopharm. 1993;39:173-191.

2. Muthu MS, Singh S. Targeted nanomedicines: Effective treatment modalities for cancer, AIDS and brain disorders. Nanomedicine. 2009;4(1):105-118.

3. Langer R. Drug delivery and targeting. Nature. 1998;392(6679):5-10.

4. Davis ME, Chen Z, Shin DM. Nanoparticle therapeutics: An emerging treatment modality for cancer. Nat Rev Drug Discov. 2008;7(9): 771-782.

5. Lammers T, Hennink W, Storm G. Tumour-targeted nanomedicines: Principles and practice. Br J Cancer. 2008;99(3):392-397.

6. Peer D, Karp JM, Hong S, Farokhzad OC, Margalit R, Langer R. Nanocarriers as an emerging platform for cancer therapy. Nat Nanotech. 2007;2(12):751-760.

7. Langer R, Folkman J. Polymers for the sustained release of proteins and other macromolecules. Nature. 1976;263(5580):797-800.

8. Duncan R. Polymer conjugates as anticancer nanomedicines. Nat Rev Cancer. 2006;6(9):688-701.

9. Lammers T, Subr V, Ulbrich K, Hennink WE, Storm G, Kiessling F. Polymeric nanomedicines for image-guided drug delivery and tumortargeted combination therapy. Nano Today. 2010;5:197-212.

10. Grund S. Polymers in drug delivery - state of the art and future trends. Adv Eng Mater. 2011. In press.

11. Gref R, Lück M, Quellec P, et al. Stealth'corona-core nanoparticles surface modified by polyethylene glycol (PEG): Influences of the corona (PEG chain length and surface density) and of the core composition on phagocytic uptake and plasma protein adsorption. Colloids Surf B Biointerfaces. 2000;18(3-4):301-313.

12. Peracchia M, Harnisch S, Pinto-Alphandary H, et al. Visualization of in vitro protein-rejecting properties of PEGylated Stealth ${ }^{\circledR}$ polycyanoacrylate nanoparticles. Biomaterials. 1999;20(14):1269-1275.

13. Athanasiou KA, Niederauer GG, Agrawal C. Sterilization, toxicity, biocompatibility and clinical applications of polylactic acid/polyglycolic acid copolymers. Biomaterials. 1996;17(2):93-102.

14. Stevanovic M, Uskokovic D. Poly(lactide-co-glycolide)-based micro and nanoparticles for the controlled drug delivery of vitamins. Curr Nanosci. 2009;5(1):1-14.

15. Jain R. The manufacturing techniques of various drug loaded biodegradable poly (lactide-co-glycolide)(PLGA) devices. Biomaterials. 2000; 21(23):2475-2490.

16. Lowe CE. Preparation of high molecular weight poly hydroxyacetic ester. US Patent 2668162, 1954.

17. Gilding D, Reed A. Biodegradable polymers for use in surgery polyglycolic/poly (actic acid) homo-and copolymers: 1. Polymer. 1979; 20(12):1459-1464.

18. Bala I, Hariharan S, Ravi K. PLGA nanoparticles in drug delivery: The state of the art. Crit Rev Ther Drug Carrier Syst. 2004;21(5):387-422.

19. Li S, McCarthy S. Influence of crystallinity and stereochemistry on the enzymatic degradation of poly (lactide)s. Macromolecules. 1999; 32(13):4454-4456.
20. Park T. Degradation of poly (D, L-lactic acid) microspheres: Effect of molecular weight. J Control Release. 1994;30(2):161-173.

21. Schliecker G, Schmidt C, Fuchs S, Kissel T. Characterization of a homologous series of D, L-lactic acid oligomers; a mechanistic study on the degradation kinetics in vitro. Biomaterials. 2003;24(21):3835-3844.

22. Panyam J, Dali MM, Sahoo SK, et al. Polymer degradation and in vitro release of a model protein from poly (D, L-lactide-co-glycolide) nanoand microparticles. J Control Release. 2003;92(1-2):173-187.

23. Barratt GM. Therapeutic applications of colloidal drug carriers. Pharm Sci Technolo Today. 2000;3(5):163-171.

24. Panyam J, Zhou W-Z, Prabha S, Sahoo SK, Labhasetwar V. Rapid endolysosomal escape of poly(DL-lactide-co-glycolide) nanoparticles: Implications for drug and gene delivery. FASEB J. 2002;16(10):1217-1226.

25. Vauthier C, Bouchemal K. Methods for the preparation and manufacture of polymeric nanoparticles. Pharm Res. 2009;26(5):1025-1058.

26. Anton N, Benoit JP, Saulnier P. Design and production of nanoparticles formulated from nano-emulsion templates - a review. J Control Release. 2008;128(3):185-199.

27. Astete C, Sabliov C. Synthesis and characterization of PLGA nanoparticles. J Biomater Sci Polym Ed. 2006;17(3):247-289.

28. Mu L, Feng S. A novel controlled release formulation for the anticancer drug paclitaxel $\left(\mathrm{Taxol}^{\mathbb{}}{ }^{\mathbb{}}\right)$ : PLGA nanoparticles containing vitamin $\mathrm{E}$ TPGS. J Control Release. 2003;86(1):33-48.

29. Chavanpatil MD, Patil Y, Panyam J. Susceptibility of nanoparticleencapsulated paclitaxel to P-glycoprotein-mediated drug efflux. Int $J$ Pharm. 2006;320(1-2):150-156.

30. Feng SS. Nanoparticles of biodegradable polymers for new-concept chemotherapy. Expert Rev Med Devices. 2004;1(1):115-125.

31. Lamprecht A, Ubrich N, Hombreiro Perez M, Lehr CM, Hoffman M, Maincent $\mathrm{P}$. Influences of process parameters on nanoparticle preparation performed by a double emulsion pressure homogenization technique. Int J Pharm. 2000;196(2):177-182.

32. Takeuchi H, Yamamoto H, Kawashima Y. Mucoadhesive nanoparticulate systems for peptide drug delivery. Adv Drug Deliv Rev. 2001;47(1): $39-54$.

33. Moinard-Chécot D, Chevalier Y, Briançon S, Fessi H, Guinebretière S. Nanoparticles for drug delivery: Review of the formulation and process difficulties illustrated by the emulsion-diffusion process. $J$ Nanosci Nanotechnol. 2006;9(10):2664-2681.

34. Murakami H, Kobayashi M, Takeuchi H, Kawashima Y. Preparation of poly (D, L-lactide-co-glycolide) nanoparticles by modified spontaneous emulsification solvent diffusion method. Int J Pharm. 1999;187(2):143-152.

35. Kwon HY, Lee JY, Choi SW, Jang Y, Kim JH. Preparation of PLGA nanoparticles containing estrogen by emulsification-diffusion method*1. Colloids Surf A PhysicochemEng Asp. 2001;182(1-3):123-130.

36. Yoo HS, Lee KH, Oh JE, Park TG. In vitro and in vivo anti-tumor activities of nanoparticles based on doxorubicin-PLGA conjugates. J Control Release. 2000;68(3):419-431.

37. Konan Y, Cerny R, Favet J, Berton M, Gurny R, Allémann E. Preparation and characterization of sterile sub-200 nm meso-tetra (4-hydroxylphenyl) porphyrin-loaded nanoparticles for photodynamic therapy. Eur J Pharm Biopharm. 2003;55(1):115-124.

38. Ibrahim H, Bindschaedler C, Doelker E, Buri P, Gurny R. Aqueous nanodispersions prepared by a salting-out process. Int J Pharm. 1992; 87(1-3):239-246.

39. Konan YN, Gurny R, Allémann E. Preparation and characterization of sterile and freeze-dried sub-200 nm nanoparticles. Int J Pharm. 2002; 233(1-2):239-252.

40. Fessi H, Puisieux F, Devissaguet JP, Ammoury N, Benita S. Nanocapsule formation by interfacial polymer deposition following solvent displacement. Int J Pharm. 1989;55(1):R1-R4.

41. Govender T, Stolnik S, Garnett M, Illum L, Davis S. PLGA nanoparticles prepared by nanoprecipitation: Drug loading and release studies of a water soluble drug. J Control Release. 1999;57(2):171-185.

42. Betancourt T, Brown B, Brannon-Peppas L. Doxorubicin-loaded PLGA nanoparticles by nanoprecipitation: Preparation, characterization and in vitro evaluation. Nanomedicine. 2007;2(2):219-232. 
43. Thioune O, Fessi H, Devissaguet J, Puisieux F. Preparation of pseudolatex by nanoprecipitation: Influence of the solvent nature on intrinsic viscosity and interaction constant. Int J Pharm. 1997;146(2):233-238.

44. Gaumet M, Vargas A, Gurny R, Delie F. Nanoparticles for drug delivery: The need for precision in reporting particle size parameters. Eur J Pharm Biopharm. 2008;69(1):1-9.

45. Dunne M, Corrigan O, Ramtoola Z. Influence of particle size and dissolution conditions on the degradation properties of polylactideco-glycolide particles. Biomaterials. 2000;21(16):1659-1668

46. Mittal G, Sahana D, Bhardwaj V, Ravi Kumar M. Estradiol loaded PLGA nanoparticles for oral administration: Effect of polymer molecular weight and copolymer composition on release behavior in vitro and in vivo. J Control Release. 2007;119(1):77-85.

47. Soppimath K, Aminabhavi T, Kulkarni A, Rudzinski W. Biodegradable polymeric nanoparticles as drug delivery devices. J Control Release. 2001;70(1-2):1-20.

48. Cheng F, Wang S, Su C, et al. Stabilizer-free poly (lactide-co-glycolide) nanoparticles for multimodal biomedical probes. Biomaterials. 2008; 29(13):2104-2112.

49. Fonseca C, Simoes S, Gaspar R. Paclitaxel-loaded PLGA nanoparticles: Preparation, physicochemical characterization and in vitro anti-tumoral activity. J Control Release. 2002;83(2):273-286.

50. Esmaeili F, Ghahremani M, Ostad S, et al. Folate-receptor-targeted delivery of docetaxel nanoparticles prepared by PLGA-PEG-folate conjugate. J Drug Target. 2008;16(5):415-423.

51. Ricci-Junior E, Marchetti J. Zinc (II) phthalocyanine loaded PLGA nanoparticles for photodynamic therapy use. Int J Pharm. 2006;310(1-2): 187-195.

52. Mo Y, Lim LY. Preparation and in vitro anticancer activity of wheat germ agglutinin (WGA)-conjugated PLGA nanoparticles loaded with paclitaxel and isopropyl myristate. J Control Release. 2005;107(1): $30-42$.

53. Panyam J, Sahoo S, Prabha S, Bargar T, Labhasetwar V. Fluorescence and electron microscopy probes for cellular and tissue uptake of poly (D, L-lactide-co-glycolide) nanoparticles. Int J Pharm. 2003; 262(1-2):1-11.

54. Yang A, Yang L, Liu W, Li Z, Xu H, Yang X. Tumor necrosis factor alpha blocking peptide loaded PEG-PLGA nanoparticles: Preparation and in vitro evaluation. Int J Pharm. 2007;331(1):123-132.

55. Dong Y, Feng S. Poly (D, L-lactide-co-glycolide)/montmorillonite nanoparticles for oral delivery of anticancer drugs. Biomaterials. 2005; 26(30):6068-6076.

56. Ravi Kumar M, Bakowsky U, Lehr C. Preparation and characterization of cationic PLGA nanospheres as DNA carriers. Biomaterials. 2004; 25(10):1771-1777.

57. Song K, Lee H, Choung I, Cho K, Ahn Y, Choi E. The effect of type of organic phase solvents on the particle size of poly (D, L-lactideco-glycolide) nanoparticles. Colloids Surf A PhysicochemEng Asp. 2006;276(1-3):162-167.

58. Chacon M, Molpeceres J, Berges L, Guzman M, Aberturas M. Stability and freeze-drying of cyclosporine loaded poly (D, L lactide-glycolide) carriers. Eur J Pharm Sci. 1999;8(2):99-107.

59. Danhier F, Lecouturier N, Vroman B, et al. Paclitaxel-loaded PEGylated PLGA-based nanoparticles: In vitro and in vivo evaluation. $J$ Control Release. 2009;133(1):11-17.

60. Garinot M, Fiévez V, Pourcelle V, et al. PEGylated PLGA-based nanoparticles targeting M cells for oral vaccination. J Control Release. 2007;120(3):195-204.

61. Kim S, Jeong J, Chun K, Park T. Target-specific cellular uptake of PLGA nanoparticles coated with poly (1-lysine)-poly (ethylene glycol)folate conjugate. Langmuir. 2005;21(19):8852-8857.

62. Si-Shen F, Li M, Guofeng H. Nanoparticles of biodegradable polymers for clinical administration of paclitaxel. Curr Med Chem. 2004; 11(4):413-424.

63. Choi S, Kim J. Design of surface-modified poly (D, L-lactideco-glycolide) nanoparticles for targeted drug delivery to bone. J Control Release. 2007;122(1):24-30.
64. Li Y, Pei Y, Zhang X, et al. PEGylated PLGA nanoparticles as protein carriers: Synthesis, preparation and biodistribution in rats. $J$ Control Release. 2001;71(2):203-211.

65. Avgoustakis K, Beletsi A, Panagi Z, Klepetsanis P, Karydas A, Ithakissios D. PLGA-mPEG nanoparticles of cisplatin: In vitro nanoparticle degradation, in vitro drug release and in vivo drug residence in blood properties. J Control Release. 2002;79(1-3):123-135.

66. Cheng J, Teply B, Sherifi I, et al. Formulation of functionalized PLGAPEG nanoparticles for in vivo targeted drug delivery. Biomaterials. 2007;28(5):869-876.

67. Esmaeili F, Hosseini-Nasr M, Rad-Malekshahi M, Samadi N, Atyabi F, Dinarvand R. Preparation and antibacterial activity evaluation of rifampicin-loaded poly lactide-co-glycolide nanoparticles. Nanomedicine. 2007;3(2):161-167.

68. Esmaeili F, Ghahremani M, Esmaeili B, Khoshayand M, Atyabi F, Dinarvand R. PLGA nanoparticles of different surface properties: Preparation and evaluation of their body distribution. Int J Pharm. 2008;349(1-2):249-255.

69. Gomez-Gaete C, Tsapis N, Besnard M, Bochot A, Fattal E. Encapsulation of dexamethasone into biodegradable polymeric nanoparticles. Int $J$ Pharm. 2007;331(2):153-159.

70. Dillen K, Vandervoort J, Van den Mooter G, Verheyden L, Ludwig A. Factorial design, physicochemical characterisation and activity of ciprofloxacin-PLGA nanoparticles. Int J Pharm. 2004;275(1-2): 171-187.

71. Panyam J, Williams D, Dash A, Leslie-Pelecky D, Labhasetwar V. Solid-state solubility influences encapsulation and release of hydrophobic drugs from PLGA/PLA nanoparticles. J Pharm Sci. 2004;93(7): 1804-1814.

72. Corrigan OI, Li X. Quantifying drug release from PLGA nanoparticulates. Eur J Pharm Sci. 2009;37(3-4):477-485.

73. Musumeci T, Ventura CA, Giannone I, et al. PLA/PLGA nanoparticles for sustained release of docetaxel. Int J Pharm. 2006;325(1-2): $172-179$.

74. Prior S, Gander B, Blarer N, et al. In vitro phagocytosis and monocytemacrophage activation with poly(lactide) and poly(lactide-co-glycolide) microspheres. Eur J Pharm Sci. 2002;15(2):197-207.

75. Zhang H, Cui W, Bei J, Wang S. Preparation of poly(lactide-co-glycolide-co-caprolactone) nanoparticles and their degradation behaviour in aqueous solution. Polym Degrad Stab. 2006;91(9):1929-1936.

76. Manuela Gaspar M, Blanco D, Cruz MEM, José Alonso M. Formulation of L-asparaginase-loaded poly(lactide-co-glycolide) nanoparticles: Influence of polymer properties on enzyme loading, activity and in vitro release. J Control Release. 1998;52(1-2):53-62.

77. Mosqueira V, Legrand P, Gulik A, et al. Relationship between complement activation, cellular uptake and surface physicochemical aspects of novel PEG-modified nanocapsules. Biomaterials. 2001;22(22): 2967-2979.

78. Storm G, Belliot SO, Daemen T, Lasic DD. Surface modification of nanoparticles to oppose uptake by the mononuclear phagocyte system. Adv Drug Deliv Rev. 1995;17(1):31-48.

79. Choi SH, Park TG. G-CSF loaded biodegradable PLGA nanoparticles prepared by a single oil-in-water emulsion method. Int J Pharm. 2006;311(1-2):223-228.

80. Rosas JE, Hern Undez RM, Gascon AR, et al. Biodegradable PLGA microspheres as a delivery system for malaria synthetic peptide SPf66. Vaccine. 2001;19(31):4445-4451.

81. Esmaeili F, Atyabi F. Preparation of PLGA nanoparticles using TPGS in the spontaneous emulsification solvent diffusion method. $J$ Exp Nanosci. 2007;2(3):183-192.

82. Utreja P, Jain S, Tiwary K. Novel drug delivery systems for sustained and targeted delivery of anti-cancer drugs: Current status and future prospects. Curr Drug Deliv. 2010;7(2):152-161.

83. Shenoy D, Little S, Langer R, Amiji M. Poly (ethylene oxide)-modified poly (-amino ester) nanoparticles as a $\mathrm{pH}$-sensitive system for tumortargeted delivery of hydrophobic drugs. 1 . In vitro evaluations. $\mathrm{Mol}$ Pharm. 2005;2(5):357-366. 
84. Miele E, Spinelli GP, Tomao F, Tomao S. Albumin-bound formulation of paclitaxel (Abraxane ${ }^{\circledR}$ ABI-007) in the treatment of breast cancer. Int J Nanomedicine. 2009;4:99-105.

85. Gradishar WJ. Albumin-bound paclitaxel: A next-generation taxane. Expert Opin Pharmacother. 2006;7(8):1041-1053.

86. Green M, Manikhas G, Orlov S, et al. Abraxane ${ }^{\circledR}$, a novel Cremophor ${ }^{\circledR}$-free, albumin-bound particle form of paclitaxel for the treatment of advanced non-small-cell lung cancer. Ann Oncol. 2006;17(8):1263-1268.

87. Soundararajan A, Bao A, Phillips W, Perez R 3rd, Goins B. Liposomal doxorubicin (Doxil): In vitro stability, pharmacokinetics, imaging and biodistribution in a head and neck squamous cell carcinoma xenograft model. Nucl Med Biol. 2009;36(5):515-524.

88. Safra T, Muggia F, Jeffers S, et al. Pegylated liposomal doxorubicin (Doxil): Reduced clinical cardiotoxicity in patients reaching or exceeding cumulative doses of $500 \mathrm{mg} / \mathrm{m}^{2}$. Ann Oncol. 2000;11(8):1029-1033.

89. Lyass O, Uziely B, Ben-Yosef R, et al. Correlation of toxicity with pharmacokinetics of pegylated liposomal doxorubicin (Doxil) in metastatic breast carcinoma. Cancer. 2000;89(5):1037-1047.

90. Jung T, Kamm W, Breitenbach A, Kaiserling E, Xiao J, Kissel T. Biodegradable nanoparticles for oral delivery of peptides: Is there a role for polymers to affect mucosal uptake? Eur J Pharm Biopharm. 2000;50(1):147-160.

91. Lü JM, Wang X, Marin-Muller C, et al. Current advances in research and clinical applications of PLGA-based nanotechnology. Expert Rev Mol Diagn. 2009;9(4):325-341.

92. Liu X, Novosad V, Rozhkova EA, et al. Surface functionalized biocompatible magnetic nanospheres for cancer hyperthermia. IEEE Trans Magn. 2007;43(6):2462-2464.

93. Van Vlerken LE, Duan Z, Little SR, Seiden MV, Amiji MM. Biodistribution and pharmacokinetic analysis of paclitaxel and ceramide administered in multifunctional polymer-blend nanoparticles in drug resistant breast cancer model. Mol Pharm. 2008;5(4):516-526.

94. Feng SS, Mu L, Chen BH, Pack D. Polymeric nanospheres fabricated with natural emulsifiers for clinical administration of an anticancer drug paclitaxel $\left(\right.$ Taxol $^{\mathbb{R}}$ ). Mater Sci Eng C. 2002;20(1-2):85-92.

95. Dong Y, Feng SS. Nanoparticles of poly (D, L-lactide)/methoxy poly (ethylene glycol) poly (D, L-lactide) blends for controlled release of paclitaxel. J Biomed Mater Res A. 2006;78(1):12-19.

96. Kim JH, Kim YS, Kim S, et al. Hydrophobically modified glycol chitosan nanoparticles as carriers for paclitaxel. J Control Release. 2006;111(1-2):228-234.

97. Xie J, Wang CH. Self-assembled biodegradable nanoparticles developed by direct dialysis for the delivery of paclitaxel. Pharm Res. 2005; 22(12):2079-2090.

98. Kim SY, Lee YM. Taxol-loaded block copolymer nanospheres composed of methoxy poly (ethylene glycol) and poly (-caprolactone) as novel anticancer drug carriers. Biomaterials. 2001;22(13): 1697-1704.

99. Zhang Z, Lee SH, Gan CW, Feng SS. In vitro and in vivo investigation on PLA-TPGS nanoparticles for controlled and sustained small molecule chemotherapy. Pharm Res. 2008;25(8):1925-1935.

100. Song C, Labhasetwar V, Cui X, Underwood T, Levy RJ. Arterial uptake of biodegradable nanoparticles for intravascular local drug delivery: Results with an acute dog model. J Control Release. 1998; 54(2):201-211.

101. Bhardwaj V, Ankola DD, Gupta SC, Schneider M, Lehr CM, Kumar MNVR. PLGA nanoparticles stabilized with cationic surfactant: Safety studies and application in oral delivery of paclitaxel to treat chemical-induced breast cancer in rat. Pharm Res. 2009;26(11):2495-2503.

102. Esmaeili F, Dinarvand R, Ghahremani MH, Ostad SN, Esmaily H, Atyabi F. Cellular cytotoxicity and in-vivo biodistribution of docetaxel poly (lactide-co-glycolide) nanoparticles. Anticancer Drugs. 2010; 21(1):43-52.

103. Mattheolabakis G, Taoufik E, Haralambous S, Roberts ML, Avgoustakis K. In vivo investigation of tolerance and antitumor activity of cisplatin-loaded PLGA-mPEG nanoparticles. Eur J Pharm Biopharm. 2009;71(2):190-195.
104. Gryparis EC, Hatziapostolou M, Papadimitriou E, Avgoustakis K. Anticancer activity of cisplatin-loaded PLGA-mPEG nanoparticles on LNCaP prostate cancer cells. Eur J Pharm Biopharm. 2007; 67(1):1-8.

105. Wust P, Hildebrandt B, Sreenivasa G, et al. Hyperthermia in combined treatment of cancer. Lancet Oncol. 2002;3(8):487-497.

106. Van der Zee J. Heating the patient: A promising approach? Ann Oncol. 2002;13(8):1173-1184.

107. Manchanda R, Fernandez-Fernandez A, Nagesetti A, McGoron AJ. Preparation and characterization of a polymeric (PLGA) nanoparticulate drug delivery system with simultaneous incorporation of chemotherapeutic and thermo-optical agents. Colloids Surf B Biointerfaces. 2010;75(1):260-267.

108. Shishodia S, Sethi G, Aggarwal BB. Curcumin: Getting back to the roots. Ann N Y Acad Sci. 2005;1056(1):206-217.

109. Mukerjee A, Vishwanatha JK. Formulation, characterization and evaluation of curcumin-loaded PLGA nanospheres for cancer therapy. Anticancer Res. 2009;29(10):3867-3875.

110. Yallapu M, Gupta B, Jaggi M, Chauhan S. Fabrication of curcumin encapsulated PLGA nanoparticles for improved therapeutic effects in metastatic cancer cells. J Colloid Interface Sci. 2010;351(1):19-29.

111. Gottesman MM. How cancer cells evade chemotherapy: Sixteenth Richard and Hinda Rosenthal Foundation award lecture. Cancer Res. 1993;53(4):747-754.

112. Davda J, Labhasetwar V. Characterization of nanoparticle uptake by endothelial cells. Int J Pharm. 2002;233(1-2):51-59.

113. Brigger I, Dubernet C, Couvreur P. Nanoparticles in cancer therapy and diagnosis. Adv Drug Deliv Rev. 2002;54(5):631-651.

114. Yan F, Zhang C, Zheng Y, et al. The effect of poloxamer 188 on nanoparticle morphology, size, cancer cell uptake, and cytotoxicity. Nanomedicine. 2010;6(1):170-178.

115. Song XR, Cai Z, Zheng Y, et al. Reversion of multidrug resistance by co-encapsulation of vincristine and verapamil in PLGA nanoparticles. Eur J Pharm Sci. 2009;37(3-4):300-305.

116. Zeisser-Labouèbe M, Lange N, Gurny R, Delie F. Hypericin-loaded nanoparticles for the photodynamic treatment of ovarian cancer. Int J Pharm. 2006;326(1-2):174-181.

117. Alexis F, Pridgen E, Molnar LK, Farokhzad OC. Factors affecting the clearance and biodistribution of polymeric nanoparticles. Mol Pharm. 2008;5(4):505-515.

118. Owens DE III, Peppas NA. Opsonization, biodistribution, and pharmacokinetics of polymeric nanoparticles. Int J Pharm. 2006;307(1): 93-102.

119. Torchilin VP, Trubetskoy VS. Which polymers can make nanoparticulate drug carriers long-circulating? Adv Drug Deliv Rev. 1995; 16(2-3):141-155.

120. Tobio M, Sanchez A, Vila A, et al. The role of PEG on the stability in digestive fluids and in vivo fate of PEG-PLA nanoparticles following oral administration. Colloids Surf B Biointerfaces. 2000;18(3-4): 315-323.

121. Stolnik S, Illum L, Davis S. Long circulating microparticulate drug carriers. Adv Drug Deliv Rev. 1995;16(2-3):195-214.

122. Ma Y, Zheng Y, Liu K, et al. Nanoparticles of poly(lactideco-glycolide)-d-a-tocopheryl polyethylene glycol 1000 succinate random copolymer for cancer treatment. Nanoscale Res Lett. 2010;5(7): 1161-1169.

123. Kabanov A, Batrakova E, Alakhov V. Pluronic ${ }^{\circledR}$ block copolymers as novel polymer therapeutics for drug and gene delivery. $J$ Control Release. 2002;82(2-3):189-212.

124. Shah N, Chaudhari K, Dantuluri P, Murthy R, Das S. Paclitaxel-loaded PLGA nanoparticles surface modified with transferrin and Pluronic ${ }^{\mathbb{R}}$ P85, an in vitro cell line and in vivo biodistribution studies on rat model. J Drug Target. 2009;17(7):533-542.

125. Parveen S, Sahoo S. Polymeric nanoparticles for cancer therapy. J Drug Target. 2008;16(2):108-123.

126. Byrne J, Betancourt T, Brannon-Peppas L. Active targeting schemes for nanoparticle systems in cancer therapeutics. Adv Drug Deliv Rev. 2008;60(15):1615-1626. 
127. Brannon-Peppas L, Blanchette J. Nanoparticle and targeted systems for cancer therapy. Adv Drug Deliv Rev. 2004;56(11):1649-1659.

128. O'Neal DP, Hirsch LR, Halas NJ, Payne JD, West JL. Photo-thermal tumor ablation in mice using near infrared-absorbing nanoparticles. Cancer Lett. 2004;209(2):171-176.

129. Ishida O, Maruyama K, Sasaki K, Iwatsuru M. Size-dependent extravasation and interstitial localization of polyethyleneglycol liposomes in solid tumor-bearing mice. Int J Pharm. 1999;190(1): 49-56.

130. Kirpotin D, Drummond D, Shao Y, et al. Antibody targeting of longcirculating lipidic nanoparticles does not increase tumor localization but does increase internalization in animal models. Cancer Res. 2006;66(13):6732-6740.

131. Bondioli L, Costantino L, Ballestrazzi A, et al. PLGA nanoparticles surface decorated with the sialic acid, $\mathrm{N}$-acetylneuraminic acid. Biomaterials. 2010;31(12):3395-3403.

132. Zheng Y, Yu B, Weecharangsan W, et al. Transferrin-conjugated lipidcoated PLGA nanoparticles for targeted delivery of aromatase inhibitor 7 $\alpha$-APTADD to breast cancer cells. Int J Pharm. 2010;390(2): 234-241.

133. Wang Z, Chui WK, Ho PC. Design of a multifunctional PLGA nanoparticulate drug delivery system: Evaluation of its physicochemical properties and anticancer activity to malignant cancer cells. Pharm Res. 2009;26(5):1162-1171.

134. Danhier F, Vroman B, Lecouturier N, et al. Targeting of tumor endothelium by RGD-grafted PLGA-nanoparticles loaded with paclitaxel. J Control Release. 2009;140(2):166-173.

135. Yoo H, Park T. Folate receptor targeted biodegradable polymeric doxorubicin micelles. J Control Release. 2004;96(2):273-283.

136. Zhang Z, Huey Lee S, Feng SS. Folate-decorated poly(lactideco-glycolide)-vitamin E TPGS nanoparticles for targeted drug delivery. Biomaterials. 2007;28(10):1889-1899.

137. Yang W, Cheng Y, Xu T, Wang X, Wen L. Targeting cancer cells with biotin-dendrimer conjugates. Eur J Med Chem. 2009;44(2):862-868.

138. Russell-Jones G, McTavish K, McEwan J, Rice J, Nowotnik D. Vitamin-mediated targeting as a potential mechanism to increase drug uptake by tumours. J Inorg Biochem. 2004;98(10):1625-1633.

139. Yellepeddi V, Kumar A, Palakurthi S. Biotinylated poly (amido) amine (pamam) dendrimers as carriers for drug delivery to ovarian cancer cells in vitro. Anticancer Res. 2009;29(8):2933.

140. Marek M, Kaiser K, Gruber H. Biotin-pyrene conjugates with poly (ethylene glycol) spacers are convenient fluorescent probes for avidin and streptavidin. Bioconjug Chem. 1997;8(4):560-566.

141. Cannizzaro S, Padera R, Langer R, et al. A novel biotinylated degradable polymer for cell-interactive applications. Biotechnol Bioeng. 1998;58(5):529-535.

142. Minko T, Paranjpe P, Qiu B, et al. Enhancing the anticancer efficacy of camptothecin using biotinylated poly (ethyleneglycol) conjugates in sensitive and multidrug-resistant human ovarian carcinoma cells. Cancer Chemother Pharmacol. 2002;50(2):143-150.
143. Patil Y, Sadhukha T, Ma L, Panyam J. Nanoparticle-mediated simultaneous and targeted delivery of paclitaxel and tariquidar overcomes tumor drug resistance. J Control Release. 2009;136(1):21-29.

144. Patil Y, Swaminathan S, Sadhukha T, Ma L, Panyam J. The use of nanoparticle-mediated targeted gene silencing and drug delivery to overcome tumor drug resistance. Biomaterials. 2010;31(2): $358-365$.

145. Kou G, Gao J, Wang H, et al. Preparation and characterization of paclitaxel-loaded PLGA nanoparticles coated with cationic SM5-1 single-chain antibody. J Biochem Mol Biol. 2007;40(5):731-739.

146. Kocbek P, Obermajer N, Cegnar M, Kos J, Kristl J. Targeting cancer cells using PLGA nanoparticles surface modified with monoclonal antibody. J Control Release. 2007;120(1-2):18-26.

147. Acharya S, Dilnawaz F, Sahoo SK. Targeted epidermal growth factor receptor nanoparticle bioconjugates for breast cancer therapy. Biomaterials. 2009;30(29):5737-5750.

148. Sun B, Ranganathan B, Feng S. Multifunctional poly (D, L-lactideco-glycolide)/montmorillonite (PLGA/MMT) nanoparticles decorated by trastuzumab for targeted chemotherapy of breast cancer. Biomaterials. 2008;29(4):475-486.

149. Gao J, Kou G, Wang H, et al. PE38 KDEL-loaded anti-HER2 nanoparticles inhibit breast tumor progression with reduced toxicity and immunogenicity. Breast Cancer Res Treat. 2009;115(1):29-41.

150. Farokhzad OC, Cheng J, Teply BA, et al. Targeted nanoparticleaptamer bioconjugates for cancer chemotherapy in vivo. Proc Natl Acad Sci U S A. 2006;103(16):6315-6320.

151. Dhar S, Gu FX, Langer R, Farokhzad OC, Lippard SJ. Targeted delivery of cisplatin to prostate cancer cells by aptamer functionalized Pt(IV) prodrug-PLGA-PEG nanoparticles. Proc Natl Acad Sci U SA. 2008;105(45):17356-17361.

152. Ricci-Júnior E, Marchetti JM. Preparation, characterization, photocytotoxicity assay of PLGA nanoparticles containing zinc (II) phthalocyanine for photodynamic therapy use. 2006;23(5):523-538.

153. Shah N, Chaudhari K, Dantuluri P, Murthy RSR, Das S. Paclitaxel-loaded PLGA nanoparticles surface modified with transferrin and Pluronic $\sup ^{\circledR} \mathrm{P} 85$, an in vitro cell line and in vivo biodistribution studies on rat model. J Drug Target. 2009;17(7):533-542.

154. Chen H, Zheng Y, Tian G, et al. Oral delivery of DMAB-modified docetaxel-loaded PLGA-TPGS nanoparticles for cancer chemotherapy. Nanoscale Res Lett. 2010;6(4):1-10.

155. Win KY, Feng SS. In vitro and in vivo studies on vitamin E TPGSemulsified poly (D, L-lactic-co-glycolic acid) nanoparticles for paclitaxel formulation. Biomaterials. 2006;27(10):2285-2291.

156. Dong Y, Feng S. Poly (D, L-lactide-co-glycolide)(PLGA) nanoparticles prepared by high pressure homogenization for paclitaxel chemotherapy. Int J Pharm. 2007;342(1-2):208-214.

157. He X, Ma J, Mercado AE, Xu W, Jabbari E. Cytotoxicity of paclitaxel in biodegradable self-assembled core-shell poly (lactide-co-glycolide ethylene oxide fumarate) nanoparticles. Pharm Res. 2008;25(7): $1552-1562$.
International Journal of Nanomedicine

\section{Publish your work in this journal}

The International Journal of Nanomedicine is an international, peerreviewed journal focusing on the application of nanotechnology in diagnostics, therapeutics, and drug delivery systems throughout the biomedical field. This journal is indexed on PubMed Central, MedLine, CAS, SciSearch ${ }^{\circledR}$, Current Contents ${ }^{\circledR} /$ Clinical Medicine,

\section{Dovepress}

Journal Citation Reports/Science Edition, EMBase, Scopus and the Elsevier Bibliographic databases. The manuscript management system is completely online and includes a very quick and fair peer-review system, which is all easy to use. Visit http://www.dovepress.com/ testimonials.php to read real quotes from published authors. 